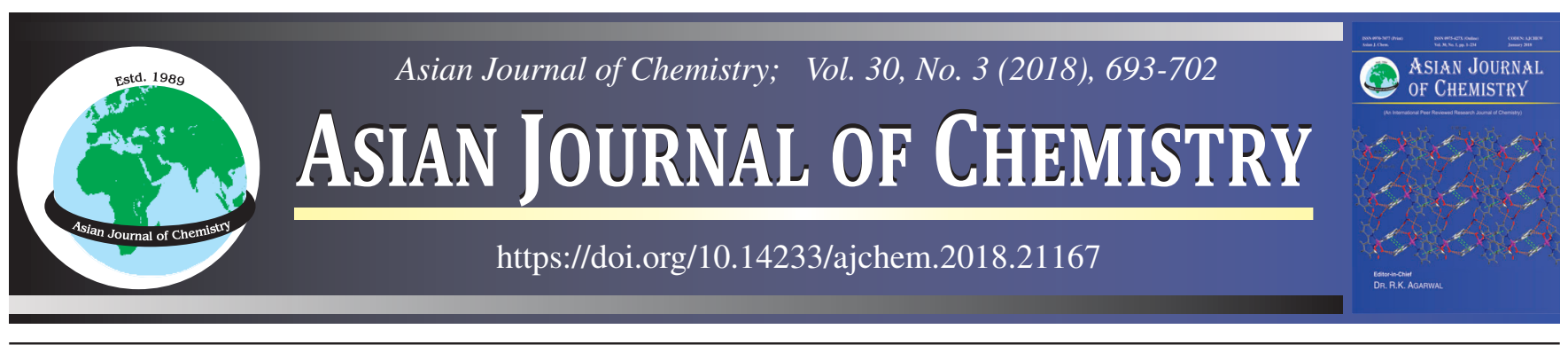

\title{
Synthesis of Some New Chrysin Derivatives and Their Biological Assessment as Antibacterial, Antibiofilm and Antifungal Agent
}

\section{S. Bhowmik ${ }^{1}$, T. Das ${ }^{1}$, S. Ghosh ${ }^{2}$, B.K. Sharma ${ }^{2}$, S. MaJumdar ${ }^{1}$ and U.C. De ${ }^{1, *}$}

${ }^{1}$ Department of Chemistry, Tripura University, Suryamaninagar-799 022, India

${ }^{2}$ Department of Microbiology, Tripura University, Suryamaninagar-799 022, India

*Corresponding author: E-mail: ucd1972@gmail.com

Received: 5 December 2017;

Accepted: 16 January 2018;

Published online: 31 January 2018;

AJC-18768

Some new derivatives of natural chrysin have been synthesized and evaluated for antibacterial, antibiofilm and antifungal activities. Three compounds, namely 2a, 2e, $2 \mathbf{i}$ showed excellent activities (MIC 14.0-18.3 $\mu \mathrm{g} / \mathrm{mL}$ ) against six bacterial and two fungal type strains while most of the other compounds showed comparatively low to moderate values of such activities. Significant antibiofilm and bactericidal activities (MBC ranges from 17-20 $\mu \mathrm{g} / \mathrm{mL}$ ) were also observed for $\mathbf{2 a}, \mathbf{2 e}, \mathbf{2} \mathbf{i}$ against pneumonia causing two bacterial strains. This study further indicated that the chrysin compounds with 7-O-alkyl type substitution were much more effective than corresponding aryl substituted congeners which signifies that 7-O position of chrysin is crucial for antimicrobial activities. Thus, this article would contribute to further design and development of potential antimicrobial agents via structural modulation of natural chrysin, which is a potential molecular skeleton with diverse biological activities.

Keywords: Chrysin, Antibiotics, Bioorganic chemistry, Drug research, Antimicrobial, Antibiofilm.

\section{INTRODUCTION}

Multi drug resistant microbial infections that have acquired in healthcare settings long back still continuing as one of the leading causes of mortality worldwide particularly in the developing countries $[1,2]$. The treatment of these microbial infections, especially in patients with compromised immunity e.g. in case of the organ transplants is a challenging problem to the existing chemotherapy [3]. Most of the pathogenic bacteria have acquired resistance to several classes of antibacterial drugs and become deadly for the host [1-4]. These antibiotic resistant bacterial infections are widely recognized as public health threats and have added a new burden and responsibilities to the scientific communities for identification and discovery of novel antimicrobial agents [1-3].

Bacteria generally exist in nature as planktonic (freely existing) and sessile forms, i.e. as a unit attached to a surface or confines in a biofilm [4-6]. Biofilm is a community of microorganisms attached to the surface of different substrates and submerged into the extracellular slimy matrix. Bacteria living in a biofilm usually have significantly different properties than a free-floating form of the same species. Biofilm provides a dense and protected environment for bacterial cell to cell communication which allows them to cooperate among themselves in various ways to produce drug resisting properties. Studies on the formation of biofilm have shown that bacterial cell membrane protein, their extracellular polysaccharides and signaling molecules play a significant role in biofilm formation [5]. Biofilm is one of the causes of numerous chronic infections, such as chronic osteomyelitis, chronic cystitis, chronic prostatitis, chronic otitis media and chronic pneumonia in patients with cystic fibrosis, etc. [5,6].

Thus, development of new types of antibacterial agents or enhancement of the activity of existing drugs is an urgent need in combating such pathogenic strains. Researchers throughout the world are engaged to develop potential antimicrobial lead compounds via chemical synthesis [7-16] as well as via the structural modulation of plant secondary metabolites [17-20]. It is well established that natural products, particularly heterocyclic compounds viz. alkaloids, flavonoids and their semi synthetic derivatives have played a vital role in drug discovery and development [2,18,21-24]. Semi synthetic flavonoid derivatives have shown to possess numerous and excellent biological activities $[17,19,20]$. Amongst various naturally occurring flavonoids, very few semi-synthetic derivatives of chrysin have been developed by different researchers and evaluated for broad spectrum biological activities viz. antimicrobial $[17,19]$, anticancer [25-28], anti-inflammatory, vasodilating, immune modulating, neuro-protective, antidiabetic and many more [17,29-31]. The encouraging biological profiles of the flavo- 
noids particularly of chrysin and in continuation of our current research interests [32] on searching and development of antimicrobial agent from natural resources led us to extend our work towards the synthesis of some new chrysin derivatives and their biological evaluations. In connection to this, it was anticipated that amines and triazole derivatives of chrysin may exhibit significant antimicrobial activity compared to the other derivatives so far reported in the literature [13,15,33-35]. Therefore, 18 different derivatives (Fig. 1) of chrysin have been synthesized (Scheme-I) through the modification of its C-7 hydroxyl group and evaluated their antimicrobial efficacy.

\section{EXPERIMENTAL}

All solvents, silica gel for column chromatography (60120 mesh) and flash chromatography (230-400 mesh) were purchased either from Merck Co., Inc., or from SRL, India. All the other reagents and chemicals were purchased from Sigma-Aldrich and were used without further purification. Thin-layer chromatography (TLC) was conducted on silica gel-coated aluminum sheets (silica gel $60 \mathrm{~F}_{254}$; Merck, Germany) and visualized under UV ( $\lambda_{254} \mathrm{~nm}$, Chromatographie Merck-12537; Merck, Germany). Flash chromatographic purifications were performed with Isolera Prime Flash Chromatography (ISO-PSV, Biotage, Sweden). Melting points were determined on a Decibel (DB-1670) digital auto melting point apparatus and were uncorrected. All the prepared compounds were characterized by spectroscopic (NMR, IR and Mass) technique and were in consistent with their desired structures. The ${ }^{1} \mathrm{H}$ and ${ }^{13} \mathrm{C}$ NMR spectra were recorded on Bruker Ultra Shield spectrometers ( 300 and $400 \mathrm{MHz}$ ). The IR spectra were recorded using $\mathrm{KBr}$ disk on a Perkin-Elmer FT-IR (Spectrum 100). Mass spectral analyses have been done on GCMS (Gas Chromatography-Mass spectrum) instruments: model Varian 220-MS/450-GC, 230V (Agilent service).

Synthesis of C-7(O) substituted chrysin amines (2a2i): The intermediates $\mathbf{1}(\mathbf{a}-\mathbf{c})$ were prepared from pure chrysin and dibromo alkanes $(1,2 ; 1,3$ and 1,4$)$ according to the method described in Scheme-I. Then to the solution of intermediate 1a (about 0.3-0.5 mmol in 5-10 $\mathrm{mL}$ anhydrous $\mathrm{CH}_{3} \mathrm{CN}$ ) was added a selected amine (1 equiv.) and anhydrous $\mathrm{K}_{2} \mathrm{CO}_{3}(1.5$ equiv.), refluxed for $24 \mathrm{~h}$ until the starting materials were disappeared on TLC. After completion of the reaction, the solvent was distilled off under reduced pressure and the residue was suspended in cold water. The product was extracted with ethyl acetate $(3 \times 10 \mathrm{~mL})$, dried over $\mathrm{Na}_{2} \mathrm{SO}_{4}$ and concentrated under reduced pressure. The residue was then subjected to chromatographic purification to obtain pure product $\mathbf{2 a - 2 i}$ (Fig. 1).

Compound 2a: Yellow solid; yield: $80 \%$; m.p.: 148-150 ${ }^{\circ} \mathrm{C} ;{ }^{1} \mathrm{H}$ NMR (400 MHz, $\left.\mathrm{CDCl}_{3}\right) \delta 1.28-1.25\left(\mathrm{~m}, 6 \mathrm{H}, \mathrm{C}_{6} \mathrm{H}_{11}\right)$, 1.99 (m, 5H, $\left.-\mathrm{C}_{6} \mathrm{H}_{11}\right), 2.72$ (s, $1 \mathrm{H}, \mathrm{OCH}_{2} \mathrm{CH}_{2} \mathrm{~N}$ ) $), 3.2$ (brs, $2 \mathrm{H}, \mathrm{OCH}_{2} \underline{\mathrm{C}}_{2} \mathrm{NH}$ ), 4.24 (brs, $2 \mathrm{H}, \mathrm{OC}_{2} \mathrm{CH}_{2} \mathrm{NH}$ ), 6.34 (s, $1 \mathrm{H}$,<smiles>O=c1cc(-c2ccccc2)oc2cc(O)cc(O)c12</smiles>

1 i) $\mathrm{R}-\mathrm{NH}_{2}$ (1.0 eqiv.)

ii) anhy. $\mathrm{K}_{2} \mathrm{CO}_{3}$ (1.5 eqiv.) acetonitrile, reflux i)

ii) Anhy. $\mathrm{K}_{2} \mathrm{CO}_{3}, 1.5 \mathrm{eq}$

Acetone \& Reflux<smiles></smiles>

$1 a(n=2) ; 1 b(n=3) ; 1 c(n=4)$<smiles>[R4]C=Cc1cc(O)c2c(=O)cc(-c3ccccc3)oc2c1</smiles>

$$
\mathbf{R}^{\prime}=\mathrm{H} ; 2 \text { (a-e, g, h) }
$$

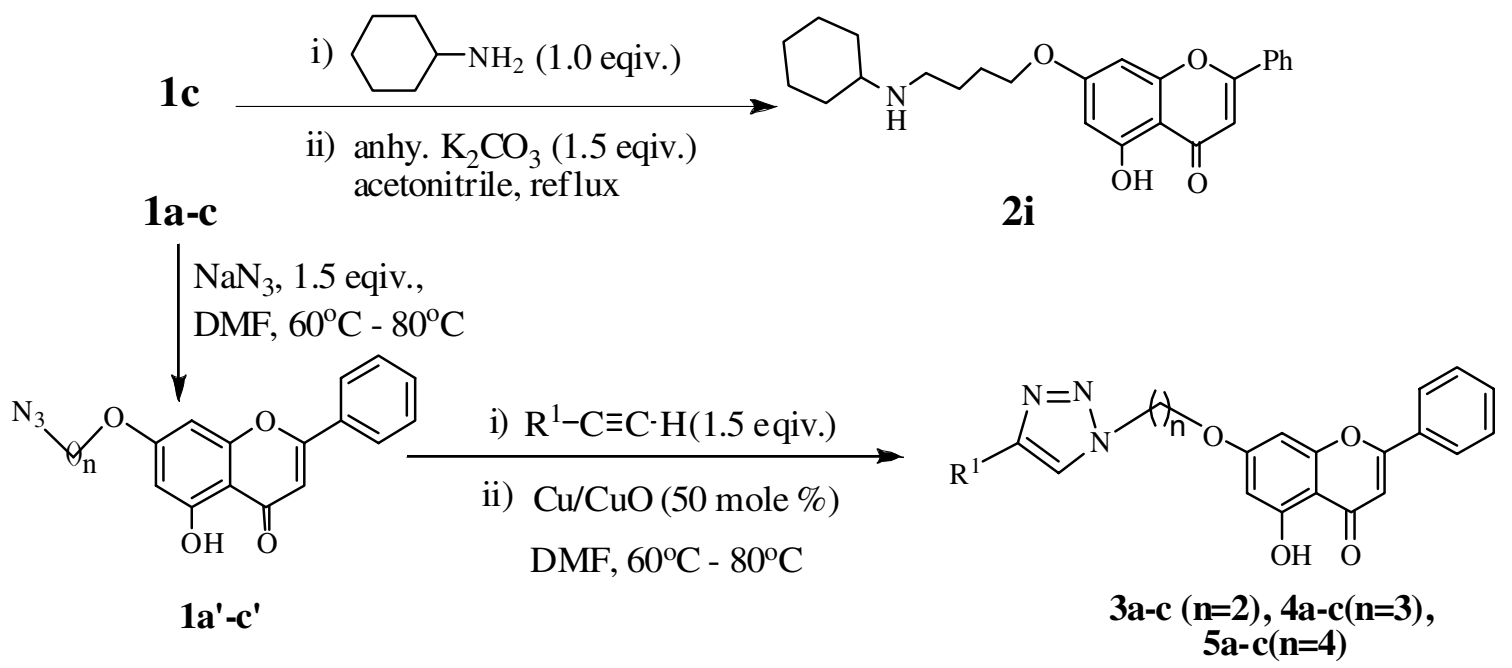

Scheme-I: Reagents and reaction conditions for the synthesis of chrysin derivatives 
<smiles>O=c1cc(-c2ccccc2)oc2cc(OCCNC3CCCCC3)cc(O)c12</smiles>

2a<smiles>O=c1cc(-c2ccccc2)oc2cc(OCCNCc3ccco3)cc(O)c12</smiles>

2d<smiles>Oc1cc(O)c(COc2cccc(-c3ccccc3)c2)cc1O</smiles>

$2 \mathrm{~g}$<smiles>O=c1cc(-c2ccccc2)oc2cc(OCCNCc3ccccc3)cc(O)c12</smiles>

2b<smiles>CCNCCOc1cc(O)c2c(=O)cc(-c3ccccc3)oc2c1</smiles>

$2 \mathrm{e}$<smiles>O=C1CC(c2ccccc2)Oc2cc(OCCNc3ccc(F)cc3)cc(O)c21</smiles>

$2 h$<smiles>Cc1ccc(NCCOc2cc(O)c3c(=O)cc(-c4ccccc4)oc3c2)c(C)c1</smiles>

2c<smiles>[Y]CN(CCCC)CC(C)(C)Oc1cc(O)c2c(=O)cc(-c3ccc4cc3CCCCC4)oc2c1</smiles>

2f<smiles></smiles>

$2 \mathrm{i}$<smiles>O=c1cc(-c2ccccc2)oc2cc(OCCn3cc(CO)nn3)cc(O)c12</smiles>

3a<smiles>O=C(O)c1cn(CCOc2cc(O)c3c(=O)cc([TlH])oc3c2)nn1</smiles>

$4 a(n=3), 5 a(n=4)$<smiles>O=c1cc(-c2ccccc2)oc2cc(OC3C=CC3n3cc(COc4ccc5ccccc5c4)nn3)cc(O)c12</smiles>

3b<smiles>Cc1cc(OCc2cn(C3CC3)nn2)cc(Oc2cc(O)c3c(=O)cc(-c4ccccc4)oc3c2)c1</smiles>

$3 c$<smiles></smiles>

$4 b(n=3), 5 b(n=4)$<smiles>Cc1cc(OCc2cn(-c3ccc(OCc4cc(O)c5c(c4)OC([TlH])C=C5O)nn3)nn2)cc(C)c1Cl</smiles>

$4 c(n=3), 5 c(n=4)$

Fig. 1. C-7(O) modified new chrysin derivatives substituted with different amines and triazoles

Ar-H), 6.49 (s, 1H, Ar-H), 6.65 (s, 1H, Ar-H), 7.52 (d, J = 6.8 $\mathrm{Hz}, 3 \mathrm{H}, \mathrm{Ar}-\mathrm{H}), 7.86$ (d, $J=6 \mathrm{~Hz}, 2 \mathrm{H}, \mathrm{Ar}-\mathrm{H}), 12.62$ (s, 1H, -OH); $\left.{ }^{13} \mathrm{C} \mathrm{NMR} \mathrm{(100} \mathrm{MHz,} \mathrm{CDCl}_{3}\right) \delta 24.8,29.6(2 \mathrm{C}), 31.5$ (2C), 44.2, 56.8, 66.3, 92.9, 98.7, 105.0, 105.9, $126.0(2 \mathrm{C})$, 129.0, 131.1 (2C), 131.8, 157.6, 162.0, 164.0, 164.2, 182.4; IR $\left(\mathrm{KBr}, v_{\max }, \mathrm{cm}^{-1}\right): 3449,3065,2929,2853,1662,1619$, 1353, 1174; MS/GCMS: Calcd. for $\mathrm{C}_{23} \mathrm{H}_{25} \mathrm{NO}_{4}: \mathrm{m} / z, 379.45$ $\left(\mathrm{M}^{+}\right)$. Found: 379 .

Compound 2b: Yellow solid; yield: $75 \%$; m.p.: 148-152 ${ }^{\circ} \mathrm{C} ;{ }^{1} \mathrm{H}$ NMR $\left(300 \mathrm{MHz}, \mathrm{CDCl}_{3}\right) \delta 2.07\left(\mathrm{~s}, 1 \mathrm{H}, \mathrm{OCH}_{2} \mathrm{CH}_{2} \mathrm{NH}\right)$, $2.97\left(\mathrm{t}, J=4.8 \mathrm{~Hz}, 2 \mathrm{H}, \mathrm{OCH}_{2} \mathrm{CH}_{2} \mathrm{NH}\right), 3.79$ (s, $\left.2 \mathrm{H},-\mathrm{CH}_{2}-\mathrm{Ar}\right)$, 4.07 (t, $\left.J=4.8 \mathrm{~Hz}, 2 \mathrm{H}, \mathrm{OCH}_{2} \mathrm{CH}_{2} \mathrm{NH}\right), 6.27$ (s, 1H, Ar-H), 6.4 (s, 1H, Ar-H), 6.57 (s, 1H, Ar-H), 7.26-7.16 (m, 5H, Ar-H), 7.44 (d, $J=0.9 \mathrm{~Hz}, 3 \mathrm{H}, \mathrm{Ar}-\mathrm{H}), 7.79$ (t, $J=6.9 \mathrm{~Hz}, 2 \mathrm{H}, \mathrm{Ar}-\mathrm{H})$, $12.61(\mathrm{~s}, 1 \mathrm{H},-\mathrm{OH}) ;{ }^{13} \mathrm{C} \mathrm{NMR}\left(75 \mathrm{MHz}, \mathrm{CDCl}_{3}\right) \delta 47.0,53.7$, 68.1, 93.1, 98.6, 105.9 (2C), 126.3 (2C), 128.5-127.1 (6C), 129.0, 131.8 (3C), 162.2 (2C), 164.8 (2C), 182.4; IR (KBr, $v_{\max }$, $\left.\mathrm{cm}^{-1}\right): 3435,3059,2926,2853,1661,1614,1353,1174$; MS/GCMS: Calcd. for $\mathrm{C}_{24} \mathrm{H}_{21} \mathrm{NO}_{4}: \mathrm{m} / z, 387.43\left(\mathrm{M}^{+}\right)$. Found: 387.
Compound 2c: Yellow solid; yield: $62 \%$; m.p.: 152$154{ }^{\circ} \mathrm{C} ;{ }^{1} \mathrm{H}$ NMR $\left(300 \mathrm{MHz}, \mathrm{CDCl}_{3}\right) \delta 2.03-2.14$ (s, 6H, Ar$\left.\mathrm{CH}_{3}\right), 3.53\left(\mathrm{t}, J=5.3 \mathrm{~Hz}, 2 \mathrm{H}, \mathrm{OCH}_{2} \underline{\mathrm{CH}}_{2} \mathrm{NH}\right), 4.15(\mathrm{t}, J=$ $\left.4.8 \mathrm{~Hz}, 2 \mathrm{H}, \mathrm{OCH}_{2} \mathrm{CH}_{2} \mathrm{NH}\right), 6.28$ (s, $\left.1 \mathrm{H}, \mathrm{Ar}-\mathrm{H}\right), 6.40$ (s, $1 \mathrm{H}$, Ar-H), 6.5 (s, 1H, Ar-H), 6.56 (s, 1H, Ar-H), 6.82 (s, 1H, $\left.\mathrm{OCH}_{2} \mathrm{CH}_{2} \mathrm{NH}\right), 6.88$ (d, $\left.J=8.1 \mathrm{~Hz}, 2 \mathrm{H}, \mathrm{Ar}-\mathrm{H}\right), 7.43$ (d, $J=$ $6.3 \mathrm{~Hz}, 3 \mathrm{H}, \mathrm{Ar}-\mathrm{H}), 7.78$ (d, $J=6.3 \mathrm{~Hz}, 2 \mathrm{H}, \mathrm{Ar}-\mathrm{H}), 12.61$ (s, $1 \mathrm{H},-\mathrm{OH}) ;{ }^{13} \mathrm{C} \mathrm{NMR}\left(75 \mathrm{MHz}, \mathrm{CDCl}_{3}\right) \delta 15.8,20.85,45.2$, 66.3, 93.2, 98.5, 105.8 (2C), 126.2 (6C), 129.0 (3C), 131.2 (2C), 131.8, 157.7, 162.2, 164.0, 164.3, 182.4; IR (KBr, $v_{\max }$, $\left.\mathrm{cm}^{-1}\right)$ : 3449.6, 3065, 2923, 2855, 1661, 1621, 1357, 1169; MS/ GCMS: Calcd. for $\mathrm{C}_{25} \mathrm{H}_{23} \mathrm{NO}_{4}: m / z 401.41\left(\mathrm{M}^{+}\right)$. Found: 401.

Compound 2d: Yellow solid; yield: $65 \%$; m.p.: 130-132 ${ }^{\circ} \mathrm{C} ;{ }^{1} \mathrm{H} \mathrm{NMR}\left(300 \mathrm{MHz}, \mathrm{CDCl}_{3}\right) \delta 2.06\left(\mathrm{~s}, 1 \mathrm{H}, \mathrm{OCH}_{2} \mathrm{CH}_{2} \mathrm{NH}\right)$, $2.96\left(\mathrm{t}, J=5.1 \mathrm{~Hz}, 2 \mathrm{H}, \mathrm{OCH}_{2} \mathrm{CH}_{2} \mathrm{NH}\right), 3.78(\mathrm{~s}, 2 \mathrm{H}$, $\mathrm{NHCH}_{2} \mathrm{C}_{4} \mathrm{H}_{3} \mathrm{O}$ ), 4.04 (t, $\left.J=5.1 \mathrm{~Hz}, 2 \mathrm{H}, \mathrm{OC}_{2} \mathrm{CH}_{2} \mathrm{NH}\right), 6.12$ $(\mathrm{d}, J=3 \mathrm{~Hz}, 1 \mathrm{H}, \mathrm{Ar}-\mathrm{H}), 6.22(\mathrm{t}, J=1.8 \mathrm{~Hz}, 1 \mathrm{H}, \mathrm{Ar}-\mathrm{H}), 6.26$ (s, 1H, Ar-H), 6.4 (s, 1H, Ar-H), 6.56 (s, 1H, Ar-H), 7.28 (d, $J=1.2 \mathrm{~Hz}, 1 \mathrm{H}, \mathrm{Ar}-\mathrm{H}), 7.43(\mathrm{dd}, J=6.9 \mathrm{~Hz}, J=3.3 \mathrm{~Hz}, 3 \mathrm{H}$, Ar-H), 7.78 (dd, $J=4.2 \mathrm{~Hz}, J=1.5 \mathrm{~Hz}, 2 \mathrm{H}, \mathrm{Ar}-\mathrm{H}), 12.62$ (s, 
$1 \mathrm{H},-\mathrm{OH}) ;{ }^{13} \mathrm{C} \mathrm{NMR}\left(75 \mathrm{MHz}, \mathrm{CDCl}_{3}\right) \delta 45.9,47.4,68.03$, 93.09, 98.6, 105.8 (2C), 107.2, 110.1, 126.2 (2C), 129.0, 131.8 (3C), 142.0 (2C), 157.7, 162.1, 164.0, 164.7, 182.4; IR (KBr, $\left.V_{\max }, \mathrm{cm}^{-1}\right): 3470,3417,2924,2851,1662,1644,1373,1179$; MS/GCMS: Calcd. for $\mathrm{C}_{22} \mathrm{H}_{19} \mathrm{NO}_{5}: \mathrm{m} / z, 377.39\left(\mathrm{M}^{+}\right)$. Found: 377.

Compound 2e: Yellow solid; yield: 70 \%; m.p.: 130-132 ${ }^{\circ} \mathrm{C} ;{ }^{1} \mathrm{H}$ NMR $\left(300 \mathrm{MHz}, \mathrm{CDCl}_{3}\right) \delta 0.86(\mathrm{t}, J=7.2 \mathrm{~Hz}, 3 \mathrm{H}$, $\mathrm{HNCH}_{2} \mathrm{CH}_{2} \mathrm{CH}_{2} \mathrm{C}_{3}$ ), 1.33 (m, $2 \mathrm{H}, \mathrm{HNCH}_{2} \mathrm{CH}_{2} \mathrm{C}_{2} \mathrm{CH}_{3}$ ), 1.52 (m, $2 \mathrm{H}, \mathrm{HNCH}_{2} \mathrm{CH}_{2} \mathrm{CH}_{2} \mathrm{CH}_{3}$ ), 1.92 (s, $1 \mathrm{H} \underline{H C H}_{2} \mathrm{CH}_{2} \mathrm{CH}_{2} \mathrm{CH}_{3}$ ), $2.68\left(\mathrm{t}, J=7.5 \mathrm{~Hz}, 2 \mathrm{H}, \mathrm{HNC}_{2} \mathrm{CH}_{2} \mathrm{CH}_{2} \mathrm{CH}_{3}\right), 3.03(\mathrm{t}, J=7.2$ $\left.\mathrm{Hz}, 2 \mathrm{H}, \mathrm{OCH}_{2} \mathrm{C}_{2} \mathrm{NH}\right), 4.11$ (t, $\left.J=4.5 \mathrm{~Hz}, 2 \mathrm{H}, \mathrm{OC}_{2} \mathrm{CH}_{2} \mathrm{NH}\right)$, $6.27(\mathrm{~s}, 1 \mathrm{H}, \mathrm{Ar}-\mathrm{H}), 6.41$ (s, 1H, Ar-H), $6.56(\mathrm{~s}, 1 \mathrm{H}, \mathrm{Ar}-\mathrm{H})$, $7.44(\mathrm{dd}, J=5.7 \mathrm{~Hz}, J=5.1 \mathrm{~Hz}, 3 \mathrm{H}, \mathrm{Ar}-\mathrm{H}), 7.77(\mathrm{dd}, J=6.0$ $\mathrm{Hz}, J=2.1 \mathrm{~Hz}, 2 \mathrm{H}, \mathrm{Ar}-\mathrm{H}), 12.62(\mathrm{~s}, 1 \mathrm{H},-\mathrm{OH}) ;{ }^{13} \mathrm{C}$ NMR $(75$ $\left.\mathrm{MHz}, \mathrm{CDCl}_{3}\right) \delta 13.8,20.3,31.1,47.72,48.9,67.0,92.9,98.6$, 105.8 (2C), 126.2 (2C), 129.0 (3C), 131.8, 162.1 (2C), 164.5 (2C), 182.4; IR (KBr, $\left.v_{\max }, \mathrm{cm}^{-1}\right)$ : 3477, 3416, 3060, 2955, 2926, 1664, 1614, 1359, 1176; MS/GCMS: Calcd. for $\mathrm{C}_{21} \mathrm{H}_{23} \mathrm{NO}_{4}: m / z$ 353.41 $\left(\mathrm{M}^{+}\right)$. Found: 353 .

Compound 2f: Yellow solid; yield: $80 \%$; m.p.: $140{ }^{\circ} \mathrm{C}$; ${ }^{1} \mathrm{H}$ NMR $\left(300 \mathrm{MHz}, \mathrm{CDCl}_{3}\right) 0.85(\mathrm{t}, J=7.2 \mathrm{~Hz}, 3 \mathrm{H}$, $\left.\mathrm{NCH}_{2} \mathrm{CH}_{2} \mathrm{CH}_{2} \mathrm{CH}_{3}\right), 1.28\left(\mathrm{~m}, 2 \mathrm{H}, \mathrm{NCH}_{2} \mathrm{CH}_{2} \mathrm{CH}_{2} \mathrm{CH}_{3}\right), 1.43$ $\left(\mathrm{m}, 2 \mathrm{H}, \mathrm{NCH}_{2} \mathrm{CH}_{2} \mathrm{CH}_{2} \mathrm{CH}_{3}\right), 2.56(\mathrm{t}, J=7.5 \mathrm{~Hz}, 2 \mathrm{H}$ $\left.\mathrm{NC}_{2} \mathrm{CH}_{2} \mathrm{CH}_{2} \mathrm{CH}_{3}\right), 2.93$ (t, $\left.J=7.2 \mathrm{~Hz}, 4 \mathrm{H}, \mathrm{OCH}_{2} \mathrm{C}_{2} \mathrm{~N}\right), 4.02$ (t, $\left.J=5.7 \mathrm{~Hz}, 4 \mathrm{H}, \mathrm{OC}_{2} \mathrm{CH}_{2} \mathrm{~N}\right), 6.24(\mathrm{~s}, 2 \mathrm{H}, \mathrm{Ar}-\mathrm{H}), 6.35(\mathrm{~s}$, 2H, Ar-H), 6.49 (s, 2H, Ar-H), 7.37 (dd, $J=6 \mathrm{~Hz}, J=3 \mathrm{~Hz}$, $6 \mathrm{H}, \mathrm{Ar}-\mathrm{H}), 7.73(\mathrm{dd}, J=6.3 \mathrm{~Hz}, J=1.2 \mathrm{~Hz}, 4 \mathrm{H}, \mathrm{Ar}-\mathrm{H}), 12.58$ (s, $2 \mathrm{H},-\mathrm{OH}) ;{ }^{13} \mathrm{C}$ NMR $\left(75 \mathrm{MHz}, \mathrm{CDCl}_{3}\right) \delta 14.0,20.4,29.5$, 53.4, 55.6 (2C), 67.6 (2C), 93.1 (2C), 98.5 (2C), 105.7 (4C), 126.2 (4C), 129.0 (2C), 131.2 (4C), 131.7 (2C), 157.6 (2C), 162.1 (2C), 163.8 (2C), 164.7 (2C), 182.3 (2C); IR (KBr, $v_{\max }$, $\mathrm{cm}^{-1}$ ): 3416, 3075, 2958, 2855, 1662, 1617, 1353, 1170; MS/ GCMS: Calcd. for $\mathrm{C}_{38} \mathrm{H}_{35} \mathrm{NO}_{8}: \mathrm{m} / z 633.69\left(\mathrm{M}^{+}\right)$. Found: 634.

Compound 2g: Yellow solid; yield: $55 \%$; m.p.: $162{ }^{\circ} \mathrm{C}$; ${ }^{1} \mathrm{H}$ NMR $\left(300 \mathrm{MHz}, \mathrm{CDCl}_{3}\right) \delta 3.58(\mathrm{t}, J=5.1 \mathrm{~Hz}, 2 \mathrm{H}$, $\left.\mathrm{OCH}_{2} \mathrm{C}_{2} \mathrm{NH}\right), 4.26\left(\mathrm{t}, J=4.8 \mathrm{~Hz}, 2 \mathrm{H}, \mathrm{OCH}_{2} \mathrm{CH}_{2} \mathrm{NH}\right), 6.29$ (s, 1H, Ar-H), 6.42 (s, 1H, Ar-H), 6.47 (s, 1H, Ar-H), 6.58 (s, $1 \mathrm{H}, \mathrm{Ar}-\mathrm{H}), 6.64\left(\mathrm{~s}, 1 \mathrm{H}, \mathrm{NHC}_{6} \mathrm{H}_{4} \mathrm{Cl}\right), 7.0(\mathrm{~m}, 1 \mathrm{H}, \mathrm{Ar}-\mathrm{H}), 7.1$ (d, $J=3.6 \mathrm{~Hz}, 2 \mathrm{H}, \mathrm{Ar}-\mathrm{H}), 7.4$ (d, $J=3.3 \mathrm{~Hz}, 3 \mathrm{H}, \mathrm{Ar}-\mathrm{H}), 7.79$ (d, $J=1.8 \mathrm{~Hz}, 2 \mathrm{H}, \mathrm{Ar}-\mathrm{H}), 12.64(\mathrm{~s}, 1 \mathrm{H},-\mathrm{OH}) ;{ }^{13} \mathrm{C}$ NMR $(75$ $\left.\mathrm{MHz}, \mathrm{CDCl}_{3}\right) \delta 43.7,67.0,93.1,98.6,105.9(2 \mathrm{C}), 114.2(2 \mathrm{C})$, 115.9 (2C), 126.2 (2C), 127.6, 129.0 (2C), 131.8, 137.8, 151.2, 157.7, 163.2, 164.0, 164.5, 182.4; IR (KBr, $\left.v_{\max }, \mathrm{cm}^{-1}\right)$ : 3445, 3416, 3025, 2958, 2852, 1666, 1617, 1339, 1179; MS/GCMS: Calcd. for $\mathrm{C}_{23} \mathrm{H}_{18} \mathrm{NO}_{4} \mathrm{Cl}: \mathrm{m} / z, 407.85\left(\mathrm{M}^{+}\right)$. Found: 408 .

Compound 2h: Shining crystalline solid; yield: $50 \%$; m.p.: $130-132{ }^{\circ} \mathrm{C} ;{ }^{1} \mathrm{H}$ NMR $\left(\mathrm{CDCl}_{3}, 300 \mathrm{MHz}\right) \delta 3.44(\mathrm{t}, J=4.8 \mathrm{~Hz}$, $\left.2 \mathrm{H}, \mathrm{OCH}_{2} \underline{\mathrm{C}}_{2} \mathrm{NH}\right), 4.12\left(\mathrm{t}, J=5.1 \mathrm{~Hz}, 2 \mathrm{H}, \mathrm{OC}_{2} \mathrm{CH}_{2} \mathrm{NH}\right)$, 6.28 (s, 1H, Ar-H), 6.4 (s, 1H, Ar-H), 6.51 (s, 1H, Ar-H), 6.53 $\left(\mathrm{s}, 1 \mathrm{H}, \mathrm{NHC}_{6} \mathrm{H}_{4} \mathrm{~F}\right), 6.57$ (t, $\left.J=2.4 \mathrm{~Hz}, 2 \mathrm{H}, \mathrm{Ar}-\mathrm{H}\right), 6.82$ (t, $J=$ $8.7 \mathrm{~Hz}, 2 \mathrm{H}, \mathrm{Ar}-\mathrm{H}), 7.44(\mathrm{~m}, 3 \mathrm{H}, \mathrm{Ar}-\mathrm{H}), 7.78(\mathrm{~d}, J=6.0 \mathrm{~Hz}$, $2 \mathrm{H}, \mathrm{Ar}-\mathrm{H}), 12.62(\mathrm{~s}, 1 \mathrm{H},-\mathrm{OH}) ;{ }^{13} \mathrm{C}$ NMR $\left(75 \mathrm{MHz}, \mathrm{CDCl}_{3}\right) \delta$ 43.7, 67.0, 93.1, 98.6, 105.9 (2C), 115.9 (2C), 126.2 (2C), 129.1, 131.2 (2C), 131.8 (3C), 143.8, 157.7, 162.2 (2C), 164.0, 164.5, 182.4; IR (KBr, $\left.v_{\max }, \mathrm{cm}^{-1}\right): 3447,3350,2926,2851$, 1672, 1617, 1333, 1177; MS/GCMS: Calcd. for $\mathrm{C}_{23} \mathrm{H}_{18} \mathrm{NO}_{4} \mathrm{~F}$ : $\mathrm{m} / z, 391.39\left(\mathbf{M}^{+}\right)$. Found: 391.
Compound 2i: Yellow solid; yield: $75 \%$; m.p.: $158-162{ }^{\circ} \mathrm{C}$; ${ }^{1} \mathrm{H}$ NMR (300 MHz, DMSO- $\left.d_{6}\right) \delta 1.13-1.023\left(\mathrm{~m}, 4 \mathrm{H}, \mathrm{C}_{6} \mathrm{H}_{11}\right)$, 1.77-1.45 (m, $\left.10 \mathrm{H}, \mathrm{C}_{6} \mathrm{H}_{11}, \mathrm{OCH}_{2} \mathrm{C}_{2} \mathrm{C}_{2} \mathrm{CH}_{2} \mathrm{NH}\right), 1.83$ (m, $1 \mathrm{H},-\mathrm{C}_{6} \mathrm{H}_{11}$ ), 2.51 (brs, $1 \mathrm{H}, \mathrm{OCH}_{2} \mathrm{CH}_{2} \mathrm{CH}_{2} \mathrm{CH}_{2} \mathrm{~N}$ ), 2.65 (t, $\left.J=6.0 \mathrm{~Hz}, 2 \mathrm{H}, \mathrm{OCH}_{2} \mathrm{CH}_{2} \mathrm{CH}_{2} \mathrm{CH}_{2} \mathrm{NH}\right), 4.03(\mathrm{t}, J=4.8 \mathrm{~Hz}$, $2 \mathrm{H}, \mathrm{OC}_{2} \mathrm{CH}_{2} \mathrm{CH}_{2} \mathrm{CH}_{2} \mathrm{NH}$ ), 6.29 (s, $\left.1 \mathrm{H}, \mathrm{Ar}-\mathrm{H}\right), 6.7$ (s, $1 \mathrm{H}$, Ar-H), 6.9 (s, 1H, Ar-H), 7.52 (d, J = 7.5Hz, 3H, Ar-H), 8.02 $(\mathrm{d}, J=6.6 \mathrm{~Hz}, 2 \mathrm{H}, \mathrm{Ar}-\mathrm{H}), 12.62(\mathrm{~s}, 1 \mathrm{H},-\mathrm{OH}) ;{ }^{13} \mathrm{C}$ NMR $(75$ MHz, DMSO- $\left.d_{6}\right) \delta 24.8,27.6(2 \mathrm{C}), 29.6$ (2C), 31.5 (2C), 44.2, $56.8,66.3,92.9,98.7,105.0,105.9,126.0$ (2C), 129.0, 131.1 (2C), 131.8, 157.6, 162.0, 164.0, 164.2, 182.4; IR (KBr, $v_{\max }$, $\left.\mathrm{cm}^{-1}\right): 3436,3065,2928,2853,1663,1612,1383,1173$; MS/ GCMS: Calcd. for $\mathrm{C}_{25} \mathrm{H}_{29} \mathrm{NO}_{4}: \mathrm{m} / z 407.50\left(\mathrm{M}^{+}\right)$. Found: 408.

Synthesis of 7-(O) substituted chrysin-triazole hybrids (3a-c, 4a-c, 5a-c): The key intermediates $\mathbf{1}(\mathbf{a}-\mathbf{c})$ was prepared according to the standard method as described in Scheme-I. Then to the solution of an intermediate 1(a-c) (about 0.2-0.5 $\mathrm{mmol}$ in about $3 \mathrm{~mL}$ anhydrous DMF) was added alkyne (1.5 equiv.), $\mathrm{Cu} / \mathrm{CuO}(50 \mathrm{~mol} \%)$ and heated at $60-80{ }^{\circ} \mathrm{C}$ for several hours until completion of the reaction was indicated on TLC. The residue was then extracted and purified by similar chromatographic techniques as before to afford 3a-c, 4a-c, 5a-c(Fig. 1).

Compound 3a: Yellow solid; yield: $75 \%$; m.p.: $186^{\circ} \mathrm{C}$; ${ }^{1} \mathrm{H}$ NMR (400 MHz, $\left.\mathrm{CDCl}_{3}\right) \delta 2.5\left(\mathrm{~s}, 1 \mathrm{H}, \mathrm{CH}_{2}-\mathrm{O} \underline{\mathrm{H}}\right), 4.49$ (brs, $2 \mathrm{H}, \mathrm{OCH}_{2} \underline{\mathrm{C}}_{2} \mathrm{~N}$ ), 4.74 (brs, $2 \mathrm{H}, \mathrm{OC}_{2} \mathrm{CH}_{2} \mathrm{~N}$ ), 4.82 (s, $2 \mathrm{H}$, $\left.\mathrm{C}_{2}-\mathrm{OH}\right), 6.35$ (s, 1H, Ar-H), 6.57 (s, 1H, Ar-H), 6.7 (s, 1H, $\mathrm{Ar}-\mathrm{H}), 7.56(\mathrm{~s}, 1 \mathrm{H}$, triazole-H), $7.9(\mathrm{~m}, 5 \mathrm{H}, \mathrm{Ar}-\mathrm{H}), 12.62(\mathrm{~s}$, $1 \mathrm{H}-\mathrm{OH}) ;{ }^{13} \mathrm{C}$ NMR $\left(100 \mathrm{MHz}, \mathrm{CDCl}_{3}\right) \delta 48.7,55.3,66.3$, 92.6, 98.1, 105.1, 105.4, 125.8, 128.6 (3C), 130.4 (2C), 131.5, 157.1 (2C), 161.4, 163.2, 163.6, 181.8; IR (KBr, $\left.v_{\max }, \mathrm{cm}^{-1}\right)$ : 3440, 2926, 2857, 1657.9, 1614, 1353; MS/GCMS: Calcd. for $\mathrm{C}_{20} \mathrm{H}_{17} \mathrm{~N}_{3} \mathrm{O}_{5}: m / z, 379.37\left(\mathrm{M}^{+}\right)$. Found: 379 .

Compound 3b: Yellow solid; yield: $45 \%$; m.p.: 160-162 ${ }^{\circ} \mathrm{C} ;{ }^{1} \mathrm{H}$ NMR $\left(400 \mathrm{MHz}, \mathrm{CDCl}_{3}\right) \delta 4.4$ (brs, $2 \mathrm{H}, \mathrm{OCH}_{2} \mathrm{C}_{2} \mathrm{~N}$ ), 4.8 (brs, $2 \mathrm{H}, \mathrm{OCH}_{2} \mathrm{CH}_{2} \mathrm{~N}$ ), 5.35 (s, $\left.2 \mathrm{H}, \mathrm{C}_{2} \mathrm{OC}_{10} \mathrm{H}_{7}\right), 6.3$ (s, 1H, Ar-H), 6.4 (s, 1H, Ar-H), 6.6 (s, 1H, Ar-H), 7.18 (s, 1H, Ar-H), 7.28 (m, 3H, Ar-H), 7.31 (d, $J=6.7 \mathrm{~Hz}, 2 \mathrm{H}, \mathrm{Ar}-\mathrm{H})$, $7.34(\mathrm{~s}, 1 \mathrm{H}$, triazole-H), $7.54(\mathrm{~d}, J=7.2 \mathrm{~Hz}, 1 \mathrm{H}, \mathrm{Ar}-\mathrm{H}), 7.75$ (d, $J=7.2 \mathrm{~Hz}, 3 \mathrm{H}, \mathrm{Ar}-\mathrm{H}), 7.87$ (dd, $J=6.4 \mathrm{~Hz}, J=4.8 \mathrm{~Hz}$, $2 \mathrm{H}, \mathrm{Ar}-\mathrm{H}), 12.75(\mathrm{~s}, 1 \mathrm{H},-\mathrm{OH}) ;{ }^{13} \mathrm{C}$ NMR $\left(100 \mathrm{MHz}, \mathrm{CDCl}_{3}\right)$ $\delta 49.4,61.9,66.3,93.0,98.4,105.9,106.2,107.7,118.7,123.9$, 126.3, 126.4, 126.8, 127.6, 129.1, 129.5 (3C), 131.1 (3C), 132.0, 134.3, 144.4, 156.0 (2C), 162.3, 163.0, 164.1, 182.4; IR $\left(\mathrm{KBr}, v_{\max }, \mathrm{cm}^{-1}\right): 3410,2927,2858,1658,1614,1357$; MS/GCMS: Calcd. for $\mathrm{C}_{30} \mathrm{H}_{23} \mathrm{~N}_{3} \mathrm{O}_{5}: \mathrm{m} / z, 505.52\left(\mathrm{M}^{+}\right)$. Found: 506.

Compound 3c: White brown solid; yield: $45 \%$; m.p.: 178$180^{\circ} \mathrm{C} ;{ }^{1} \mathrm{HNMR}\left(400 \mathrm{MHz}, \mathrm{CDCl}_{3}\right) \delta 2.3\left(\mathrm{~s}, 6 \mathrm{H}, \mathrm{OC}_{6} \mathrm{H}_{2}\left(\mathrm{C}_{3}\right)_{2} \mathrm{Cl}\right)$, 4.4 (brs, $2 \mathrm{H}, \mathrm{OCH}_{2} \mathrm{CH}_{2} \mathrm{~N}$ ), 4.8 (brs, $2 \mathrm{H}, \mathrm{OC}_{2} \mathrm{CH}_{2} \mathrm{~N}$ ), 5.1 (s, $\left.2 \mathrm{H}, \mathrm{C}_{2} \mathrm{OC}_{6} \mathrm{H}_{2}\left(\mathrm{Me}_{2}\right) \mathrm{Cl}\right), 6.3$ (s, 1H, Ar-H), 6.4 (s, 1H, Ar-H), $6.6(\mathrm{~s}, 1 \mathrm{H}, \mathrm{Ar}-\mathrm{H}), 6.7$ (s, 2H, Ar-H), $7.54(\mathrm{~s}, 1 \mathrm{H}$, triazole-H), 7.78 (brs, 3H, Ar-H), 7.8 (d, $J=6 \mathrm{~Hz}, 2 \mathrm{H}, \mathrm{Ar}-\mathrm{H}), 12.75$ (s, $1 \mathrm{H},-\mathrm{OH}) ;{ }^{13} \mathrm{C}$ NMR $\left(100 \mathrm{MHz}, \mathrm{CDCl}_{3}\right) \delta 20.9(2 \mathrm{C}), 49.4$, 61.9, 66.2, 92.2, 98.2, 105.7 (2C), 114.2 (2C), 123.1, 126.8, 129.1 (3C), 131.2 (3C), 137.2 (2C), 142.0, 158.0, 159.8, 162.2, 164.1, 165.0, 182.4; IR (KBr, $\left.v_{\max }, \mathrm{cm}^{-1}\right)$ : 3435, 2920, 2853, 1651.7, 1614, 1349.7; MS/GCMS: Calcd. for $\mathrm{C}_{28} \mathrm{H}_{24} \mathrm{~N}_{3} \mathrm{O}_{5} \mathrm{Cl}$ : $\mathrm{m} / \mathrm{z} 517.96\left(\mathbf{M}^{+}\right)$. Found: 518. 
Compound 4a: Light yellow solid; yield: $98 \%$; m.p.: 170 ${ }^{\circ} \mathrm{C}$; ${ }^{1} \mathrm{HNMR}\left(400 \mathrm{MHz}, \mathrm{CDCl}_{3}\right) \delta 2.47\left(\mathrm{~m}, 2 \mathrm{H}, \mathrm{OCH}_{2} \mathrm{CH}_{2} \mathrm{CH}_{2} \mathrm{~N}\right)$, 4.03 (brs, $2 \mathrm{H}, \mathrm{OCH}_{2} \mathrm{CH}_{2} \mathrm{CH}_{2} \mathrm{~N}$ ), 4.6 (brs, $2 \mathrm{H}, \mathrm{OC}_{2} \mathrm{CH}_{2} \mathrm{CH}_{2} \mathrm{~N}$ ), $6.3(\mathrm{~s}, 1 \mathrm{H}, \mathrm{Ar}-\mathrm{H}), 6.4(\mathrm{~s}, 1 \mathrm{H}, \mathrm{Ar}-\mathrm{H}), 6.6(\mathrm{~s}, 1 \mathrm{H}, \mathrm{Ar}-\mathrm{H}), 7.54(\mathrm{~d}$, $J=6.4 \mathrm{~Hz}, 3 \mathrm{H}, \mathrm{Ar}-\mathrm{H}), 7.7(\mathrm{~s}, 1 \mathrm{H}$, triazole- $\mathrm{H}), 7.8(\mathrm{~d}, J=6 \mathrm{~Hz}$, $2 \mathrm{H}, \mathrm{Ar}-\mathrm{H}), 12.73$ (s, 2H, -OH, -COOH) ${ }^{13} \mathrm{C}$ NMR $(100 \mathrm{MHz}$, $\left.\mathrm{CDCl}_{3}\right) \delta 29.6,46.7,64.6,92.8,98.6,105.9(2 \mathrm{C}), 123.9,129.1$ (3C), 131.9 (3C), 133.9, 157.7, 162.1, 164.0, 164.2, 182.4 (2C); IR (KBr, $\left.v_{\max }, \mathrm{cm}^{-1}\right): 3415,2926,2857,1657,1614,1379$; MS/GCMS: Calcd. for $\mathrm{C}_{21} \mathrm{H}_{17} \mathrm{~N}_{3} \mathrm{O}_{6}: \mathrm{m} / z 407.38\left(\mathrm{M}^{+}\right)$. Found: 407.

Compound 4b: Light yellow solid; yield: $55 \%$; m.p.: 164 ${ }^{\circ} \mathrm{C}$; ${ }^{1} \mathrm{HNMR}\left(400 \mathrm{MHz}, \mathrm{CDCl}_{3}\right) \delta 2.45\left(\mathrm{~m}, 2 \mathrm{H}, \mathrm{OCH}_{2} \mathrm{CH}_{2} \mathrm{CH}_{2} \mathrm{~N}\right)$, $4.0\left(\mathrm{t}, J=4.8 \mathrm{~Hz}, 2 \mathrm{H}, \mathrm{OCH}_{2} \mathrm{CH}_{2} \mathrm{CH}_{2} \mathrm{~N}\right), 4.6(\mathrm{t}, J=6.4 \mathrm{~Hz}$, $2 \mathrm{H}, \mathrm{OC}_{2} \mathrm{CH}_{2} \mathrm{CH}_{2} \mathrm{~N}$ ), 5.35 (s, $\left.2 \mathrm{H}, \underline{\mathrm{C}}_{2} \mathrm{OC}_{10} \mathrm{H}_{7}\right), 6.3$ (s, $1 \mathrm{H}$, Ar-H), 6.4 (s, 1H, Ar-H), 6.6 (s, 1H, Ar-H), 7.18 (s, 1H, Ar$\mathrm{H}), 7.28(\mathrm{~m}, 3 \mathrm{H}, \mathrm{Ar}-\mathrm{H}), 7.3(\mathrm{~d}, J=6.7 \mathrm{~Hz}, 2 \mathrm{H}, \mathrm{Ar}-\mathrm{H}), 7.34(\mathrm{~s}$, $1 \mathrm{H}$, triazole-H), $7.54(\mathrm{~d}, J=7.2 \mathrm{~Hz}, 1 \mathrm{H}, \mathrm{Ar}-\mathrm{H}), 7.75(\mathrm{~d}, J=$ $7.2 \mathrm{~Hz}, 3 \mathrm{H}, \mathrm{Ar}-\mathrm{H}), 7.85$ (dd, $J=6.4 \mathrm{~Hz}, J=4.8 \mathrm{~Hz}, 2 \mathrm{H}, \mathrm{Ar}-$ $\mathrm{H}), 12.72(\mathrm{~s}, 1 \mathrm{H},-\mathrm{OH}) ;{ }^{13} \mathrm{C} \mathrm{NMR}\left(100 \mathrm{MHz}, \mathrm{CDCl}_{3}\right) \delta 29.5$, 49.4, 61.9, 64.6, 92.9, 98.6, 105.8, 105.9, 107.1, 118.7, 123.8, 126.2, 126.4, 126.8, 127.6, 129.1 (3C), 131.1 (3C), 131.9, 134.3 (2C), 144.2, 156.0, 157.7, 162.1, 164.1, 164.2, 182.4; IR (KBr, $\left.v_{\max }, \mathrm{cm}^{-1}\right): 3423,2926,2851.8,1658,1614,1382$; MS/GCMS: Calcd. for $\mathrm{C}_{31} \mathrm{H}_{25} \mathrm{~N}_{3} \mathrm{O}_{5}: \mathrm{m} / z 519.55\left(\mathrm{M}^{+}\right)$. Found: 520.

Compound 4c: Brown solid; yield: $52 \%$; m.p.: 158-160 ${ }^{\circ} \mathrm{C}$; ${ }^{1} \mathrm{H} \mathrm{NMR}\left(400 \mathrm{MHz}, \mathrm{CDCl}_{3}\right) \delta 2.3\left(\mathrm{~s}, 6 \mathrm{H}, \mathrm{OC}_{6} \mathrm{H}_{2}\left(\mathrm{C}_{3}\right)_{2} \mathrm{Cl}\right)$, $2.46\left(\mathrm{~m}, 2 \mathrm{H}, \mathrm{OCH}_{2} \mathrm{C}_{2} \mathrm{CH}_{2} \mathrm{~N}\right), 4.0$ (brs, $2 \mathrm{H}, \mathrm{OCH}_{2} \mathrm{CH}_{2} \mathrm{CH}_{2} \mathrm{~N}$ ), 4.6 (brs, $2 \mathrm{H}, \mathrm{OCH}_{2} \mathrm{CH}_{2} \mathrm{CH}_{2} \mathrm{~N}$ ), 5.1 (s, $2 \mathrm{H}, \mathrm{CH}_{2} \mathrm{OC}_{6} \mathrm{H}_{2}$ $\left.\left(\mathrm{CH}_{3}\right)_{2} \mathrm{Cl}\right), 6.3$ (s, 1H, Ar-H), 6.4 (s, 1H, Ar-H), 6.6 (s, 1H, Ar$\mathrm{H}), 6.69(\mathrm{~s}, 2 \mathrm{H}, \mathrm{Ar}-\mathrm{H}), 7.53(\mathrm{~s}, 1 \mathrm{H}$, triazole-H), $7.62(\mathrm{brs}, 3 \mathrm{H}$, Ar-H), $7.8(\mathrm{~d}, J=6 \mathrm{~Hz}, 2 \mathrm{H}, \mathrm{Ar}-\mathrm{H}), 12.73(\mathrm{~s}, 1 \mathrm{H},-\mathrm{OH}) ;{ }^{13} \mathrm{C}$ NMR $\left(100 \mathrm{MHz}, \mathrm{CDCl}_{3}\right) \delta 20.9(2 \mathrm{C}), 29.5,47.0,62.0,64.7$, 92.9, 98.5, 105.9 (2C), 114.6 (2C), 123.1, 126.8, 129.1 (3C), 131.1 (3C), 137.2 (2C), 144.2, 155.9, 157.7, 162.1, 164.0, 164.2, 182.4; IR (KBr, $\left.v_{\max }, \mathrm{cm}^{-1}\right): 3409,2929,2857.5,1658$, 1614, 1348; MS/GCMS (m/z): Calcd. for $\mathrm{C}_{29} \mathrm{H}_{26} \mathrm{~N}_{3} \mathrm{O}_{5} \mathrm{Cl}: \mathrm{m} / z$ $531.99\left(\mathrm{M}^{+}\right)$. Found: 532.

Compound 5a: Yellow solid; yield: $67 \%$; m.p.: $182-184{ }^{\circ} \mathrm{C}$; ${ }^{1} \mathrm{HNMR}\left(400 \mathrm{MHz}, \mathrm{CDCl}_{3}\right) \delta 1.85$ (brs, $2 \mathrm{H}, \mathrm{OCH}_{2} \mathrm{CH}_{2} \mathrm{C}_{2} \mathrm{CH}_{2} \mathrm{~N}$ ), 2.16 (brs, $2 \mathrm{H}, \mathrm{OCH}_{2} \mathrm{CH}_{2} \mathrm{CH}_{2} \mathrm{CH}_{2} \mathrm{~N}$ ), 4.06 (brs, $2 \mathrm{H}$ $\mathrm{OCH}_{2} \mathrm{CH}_{2} \mathrm{CH}_{2} \mathrm{C}_{2} \mathrm{~N}$ ), 4.5 (brs, $2 \mathrm{H}, \mathrm{OC}_{2} \mathrm{CH}_{2} \mathrm{CH}_{2} \mathrm{CH}_{2} \mathrm{~N}$ ), 6.3 (s, 1H, Ar-H), 6.4 (s, 1H, Ar-H), 6.6 (s, 1H, Ar-H), 7.6 (d, $J=$ $6.5 \mathrm{~Hz}, 3 \mathrm{H}, \mathrm{Ar}-\mathrm{H}), 7.7$ (brs, $1 \mathrm{H}$, triazole- $\mathrm{H}), 7.89$ (d, $J=5.2$ $\mathrm{Hz}, 2 \mathrm{H}, \mathrm{Ar}-\mathrm{H}), 12.72$ (s, 2H, -OH, -COOH); ${ }^{13} \mathrm{C}$ NMR (100 $\left.\mathrm{MHz}, \mathrm{CDCl}_{3}\right) \delta 25.9,27.1,49.7,67.5,92.9,98.5,105.8$ (2C), 123.3, 131.2 (3C), 131.8 (3C), 133.9, 157.7, 162.1, 164.0, 164.6, 182.4 (2C); IR (KBr, $\left.v_{\max }, \mathrm{cm}^{-1}\right): 3440,2926,2857,1660,1614$, 1373; MS/GCMS: Calcd. for $\mathrm{C}_{22} \mathrm{H}_{19} \mathrm{~N}_{3} \mathrm{O}_{6}: \mathrm{m} / z 421.40\left(\mathrm{M}^{+}\right)$. Found: 421.

Compound 5b: Light yellow solid; yield: $60 \%$; m.p.: 166-168 ${ }^{\circ} \mathrm{C} ;{ }^{1} \mathrm{H}$ NMR $\left(400 \mathrm{MHz}, \mathrm{CDCl}_{3}\right) \delta 1.85(\mathrm{~m}, 2 \mathrm{H}$, $\mathrm{OCH}_{2} \mathrm{CH}_{2} \mathrm{CH}_{2} \mathrm{CH}_{2} \mathrm{~N}$ ), 2.15 (m, 2H, OCH${ }_{2} \underline{\mathrm{H}}_{2} \mathrm{CH}_{2} \mathrm{CH}_{2} \mathrm{~N}$ ), 4.03 (brs, 2H, $\quad \mathrm{OCH}_{2} \mathrm{CH}_{2} \mathrm{CH}_{2} \mathrm{CH}_{2} \mathrm{~N}$ ), 4.47 (brs, 2H, $\mathrm{OC}_{2} \mathrm{CH}_{2} \mathrm{CH}_{2} \mathrm{CH}_{2} \mathrm{~N}$ ), 5.3 (s, 2H, $\left.\underline{\mathrm{CH}}_{2} \mathrm{OC}_{10} \mathrm{H}_{7}\right), 6.3$ (s, $1 \mathrm{H}, \mathrm{Ar}-$ H), 6.4 (s, 1H, Ar-H), 6.6 (s, 1H, Ar-H), 7.19 (s, 1H, Ar-H), $7.3(\mathrm{~m}, 3 \mathrm{H}, \mathrm{Ar}-\mathrm{H}), 7.34$ (s, $1 \mathrm{H}$, triazole-H), 7.4 (t, $J=6.8 \mathrm{~Hz}$,
2H, Ar-H), 7.54 (d, $J=7.2 \mathrm{~Hz}, 1 \mathrm{H}, \mathrm{Ar}-\mathrm{H}), 7.75(\mathrm{~d}, J=7.3 \mathrm{~Hz}$, $3 \mathrm{H}, \mathrm{Ar}-\mathrm{H}), 7.88(\mathrm{dd}, J=6.8 \mathrm{~Hz}, J=4.9 \mathrm{~Hz}, 2 \mathrm{H}, \mathrm{Ar}-\mathrm{H}), 12.72$ (s, $1 \mathrm{H},-\mathrm{OH}) ;{ }^{13} \mathrm{C}$ NMR $\left(100 \mathrm{MHz}, \mathrm{CDCl}_{3}\right) \delta 25.9,27.0,49.9$, 62.0, 67.4, 93.0, 98.4, 105.8, 107.0, 118.7, 123.9, 126.2, 126.4, 126.8, 127.6, 129.0, 129.5 (3C), 131.2(3C), 131.8, 134.3 (2C), 144.3, 156.0, 157.7, 162.1, 164.0, 164.6, 182.4; IR (KBr, $v_{\max }$, $\left.\mathrm{cm}^{-1}\right):$ 3430, 2926, 2857, 1657.9, 1614, 1372; MS/GCMS: Calcd. for $\mathrm{C}_{32} \mathrm{H}_{27} \mathrm{~N}_{3} \mathrm{O}_{5}: \mathrm{m} / z 533.57\left(\mathrm{M}^{+}\right)$. Found: 534 .

Compound 5c: White solid; yield: $85 \%$; m.p.: $148{ }^{\circ} \mathrm{C}$; ${ }^{1} \mathrm{HNMR}\left(400 \mathrm{MHz}, \mathrm{CDCl}_{3}\right) \delta 1.7\left(\mathrm{~m}, 2 \mathrm{H}, \mathrm{OCH}_{2} \mathrm{CH}_{2} \mathrm{C}_{2} \mathrm{CH}_{2} \mathrm{~N}\right)$, $1.8\left(\mathrm{~m}, 2 \mathrm{H}, \mathrm{OCH}_{2} \mathrm{CH}_{2} \mathrm{CH}_{2} \mathrm{CH}_{2} \mathrm{~N}\right), 2.3\left(\mathrm{~s}, 6 \mathrm{H}, \mathrm{OC}_{6} \mathrm{H}_{2}\left(\mathrm{C}_{3}\right)_{2} \mathrm{Cl}\right), 4.0$ (brs, $2 \mathrm{HOCH}_{2} \mathrm{CH}_{2} \mathrm{CH}_{2} \mathrm{CH}_{2} \mathrm{~N}$ ), 4.4 (brs, $2 \mathrm{H}, \mathrm{OCH}_{2} \mathrm{CH}_{2} \mathrm{CH}_{2} \mathrm{CH}_{2} \mathrm{~N}$ ), $5.1\left(\mathrm{~s}, 2 \mathrm{H}, \mathrm{C}_{2} \mathrm{OC}_{6} \mathrm{H}_{2}\left(\mathrm{Me}_{2}\right) \mathrm{Cl}\right), 6.3(\mathrm{~s}, 1 \mathrm{H}, \mathrm{Ar}-\mathrm{H}), 6.4(\mathrm{~s}, 1 \mathrm{H}$, Ar- $\mathrm{H}), 6.6(\mathrm{~s}, 1 \mathrm{H}, \mathrm{Ar}-\mathrm{H}), 6.7(\mathrm{~s}, 2 \mathrm{H}, \mathrm{Ar}-\mathrm{H}), 7.53(\mathrm{~s}, 1 \mathrm{H}$, triazoleH), 7.63 (brs, 3H, Ar-H), 7.8 (s, 2H, Ar-H), $12.72(\mathrm{~s}, 1 \mathrm{H},-\mathrm{OH})$; ${ }^{13} \mathrm{C}$ NMR (100 MHz, $\left.\mathrm{CDCl}_{3}\right) \delta 20.9$ (2C), 25.9, 27.0, 49.9, 62.1, 67.4, 92.9, 98.5, 105.8 (2C), 114.7 (2C), 122.5, 126.8, 129.1 (3C), 131.8 (3C), 137.2 (2C), 144.3, 155.9, 157.7, 162.2, 164.0, 164.6, 182.4; IR (KBr, $\left.v_{\max }, \mathrm{cm}^{-1}\right)$ : 3402, 2923, 2855 , 1657.9, 1614, 1318; MS/GCMS: Calcd. for $\mathrm{C}_{30} \mathrm{H}_{28} \mathrm{~N}_{3} \mathrm{O}_{5} \mathrm{Cl}: \mathrm{m} / \mathrm{z}$ $546.01\left(\mathrm{M}^{+}\right)$. Found: 546.

Antimicrobial activity by Agar well diffusion method: Antimicrobial activities of all the derivatives were evaluated against different bacterial and fungal type strains by agar well diffusion method [36]. The plates were prepared in $90 \mathrm{~mm}$ Petri dish with $22 \mathrm{~mL}$ nutrient agar of $3 \mathrm{~mm}$ depth. A lawn culture of the test bacterial and fungal strains $(100 \mu \mathrm{L})$ containing $10^{6} \mathrm{CFU} / \mathrm{mL}$ were made and waited for $15 \mathrm{~min}$ to absorb the culture to the medium. Agar wells ( $6 \mathrm{~mm}$ diameter) were bored by sterilized $1000 \mu \mathrm{L}$ micro tips and then $100 \mu \mathrm{L}$ solution (in DMSO) of each test compound ( $1 \mathrm{mg} / \mathrm{mL}$ concentration) was poured into the wells. The plates for antibacterial studies were incubated at $37^{\circ} \mathrm{C}$ for $18-24 \mathrm{~h}$ and for antifungal studies plates were incubated at $30^{\circ} \mathrm{C}$ for $72-96 \mathrm{~h}$. To ensure that the solvent had no effect on bacterial and fungal growth, a control experiment was performed at the same time by testing the medium supplemented with all the solvents used in the experiments. The inhibition zone of bacterial growth for each compound against a particular stain was taken as the mean value of three individual replicates.

Determination of MIC and MBC by micro dilution method: Assays of minimum inhibitory concentration (MIC) were performed only for the potent derivatives viz. 2a, 2e and $\mathbf{2 i}$, according to the standard micro dilution method using different culture media viz. Todd Hewitt broth and Luria Bertani broth for bacteria and YPD broth for fungi following the guidelines of NCCLS. Briefly, test compounds were first dissolved in dimethyl sulfoxide and then $100 \mu \mathrm{L}$ of the bacterial culture of $10^{6} \mathrm{CFU} / \mathrm{mL}$ were added in each tube. The concentration ranges $10-100 \mu \mathrm{g} / \mathrm{mL}$ for all the selected compounds were used in MIC determination. In each test tube a definite (but different in different tubes) volume of a test compound was added and then the total volume was adjusted to $2 \mathrm{~mL}$ with additional specific broth media. After completion of additions all the test tubes were incubated at $37{ }^{\circ} \mathrm{C}$ for $18-24 \mathrm{~h}$. The medium containing $2 \%$ DMSO only was also inoculated with the test organisms in separate test tubes and kept as a control and a same but un-inoculated media was kept as sterility 
control. The MIC was recorded by detecting the lowest concentration that fully inhibits the visible growth of the organisms detected by the unaided eyes [36]. All the experiments were repeated for three times. The minimum bactericidal concentration (MBC) was also determined by sub-culturing the samples in Petri dish containing Luria Bertania Agar (Hi-media) from the test tubes of MIC doses as well as with the high concentrations then MIC. The MBC was detected by observing the lowest concentration higher than the MIC associated with no bacterial growth in the culture plates. The $\mathrm{MBC}$ was categorized at the concentration where the bacterial cell count reduction was found $\geq 99 \%$. The entire assay was also performed in triplicate for each organism.

Determination of antibiofilm activity by crystal violet assay against pneumococci: The anti-biofilm activity has been evaluated against Streptococcus pneumoniae and Klebsiella pneumoniae. Both the strains were sub cultured in LuriaBertani agar (Hi-media) and Todd Hewitt agar (Hi-media) respectively and incubated aerobically at $37^{\circ} \mathrm{C}$ for $24 \mathrm{~h}$. Biofilm formation of the controls and antibiofilm activity of $\mathbf{2 a}, \mathbf{2 e}$ and $2 \mathbf{i}$ were determined by crystal violet assay using 96 microtiter plates [30]. Briefly, one colony from each strain was grown in Luria-Bertani broth and Todd Hewitt broth overnight at $37{ }^{\circ} \mathrm{C}$ in a shaker incubator at $200 \mathrm{rpm}$. Then $50 \mu \mathrm{L}$ of the culture was added to the both broth $(5 \mathrm{~mL})$ and an over day culture was grown since 2-3 $\mathrm{h}$ in a shaker incubator with $200 \mathrm{rpm}$ at $37{ }^{\circ} \mathrm{C}$ maintaining optical density (OD) at 600 at this stage. Next, 96-well tissue culture plate was inoculated with $200 \mu \mathrm{L}$ of over day culture treated with the different concentration of test compounds and has grown at $37^{\circ} \mathrm{C}$ overnight. After that, $180 \mathrm{~mL}$ of each well was aspirated and the plate was washed with PBS and air dried. Then $200 \mathrm{~mL}$ of $0.1 \%$ aqueous crystal violet $(\mathrm{CV})$ was poured into each well and left for $30 \mathrm{~min}$. After that $180 \mathrm{~mL}$ of each well was aspirated, washed with PBS and air dried. Then $200 \mathrm{~mL}$ of $95 \%$ ethanol was added to each well to elute $\mathrm{CV}$ and left for $30 \mathrm{~min}$. Finally, the plate was scanned with a microplate reader at $540 \mathrm{~nm}$. All the absorbances were recorded, the results were thoroughly analyzed (Mean \pm SEM) and the significant differences of absorbances were plotted against concentration using Microsoft Excel 2007.

Cell viability staining assay of the pneumococcal biofilm by acridine orange and ethidium bromide: To assess the effects of potential compounds on bacterial cell viability, an acridine orange/ethidium bromide staining assay was done according to the standard method $[37,38]$. The acridine orange/ethidium bromide reagent was made by mixing of $100 \mu \mathrm{g} / \mathrm{mL}$ of ethidium bromide and $100 \mu \mathrm{g} / \mathrm{mL}$ of acridine orange in PBS. The cells were inoculated in media containing Petri dishes and covered with cover slips. The microorganism in culture media was then allowed to adhere and spread into the surface of the cover slips in the Petri dishes, which were then exposed to test compounds in different concentration ranging from $10-100 \mu \mathrm{g} / \mathrm{mL}$ and incubated for $24-36 \mathrm{~h}$ at $37^{\circ} \mathrm{C}$. An untreated (not treated with test compound) cell culture was also maintained as control. All the respective cover slips of bacterial strain were rinsed with PBS and dried. Cover slips were then stained with the previously prepared acridine orange/ethidium bromide dye solution for 1 min under gentle agitation and subsequently viewed and imaged using fluorescence microscope (Leica Biosystems).

Hemolytic activity study of the compounds: The hemolytic activities of the potential compounds were assayed by agar diffusion technique on blood agar. Briefly, blood agar was prepared in Petri plates and wells measuring $5 \mathrm{~mm}$ were bored using $1000 \mu \mathrm{L}$ sterile micropipette on the blood agar. The wells were filled with $40 \mu \mathrm{L}(1 \mathrm{mg} / \mathrm{mL})$ of selected compound in DMSO and the plates were incubated at $37{ }^{\circ} \mathrm{C}$ for $24 \mathrm{~h}$. A separate well was also maintained with amoxicillin as standard.

\section{RESULTS AND DISCUSSION}

In chrysin C-5-hydroxyl group is relatively less reactive than $\mathrm{C}-7-\mathrm{OH}$ due to steric effect and strong intra-molecular $\mathrm{H}$-bonding between $\mathrm{C}-5-\mathrm{OH}$ and the carbonyl oxygen (at C-4) [33]. Thus, C-7-hydroxyl group of chrysin was selectively reacted with dibromoalkane $(1,2 ; 1,3$ and 1,4$)$ to obtain corresponding C-7-O-bromoalkyl chrysin as intermediates 1a-1c (Scheme-I). These intermediates were then reacted with different aliphatic and aromatic amines to obtain the series of chrysinamine conjugates 2a-2i (Fig. 1). In another attempt, bromoalkyl chrysin intermediates were converted into azides $\mathbf{1 a}^{\prime}-\mathbf{1} \mathbf{c}^{\prime}$ (Scheme-I). On the other hand propargyl ether of various substituted phenols have been prepared separately and reacted [34] with the intermediates $\mathbf{1 a}^{\prime}-\mathbf{1} \mathbf{c}^{\prime}$ (Scheme-I) to obtain the series of chrysin-triazole conjugates $\mathbf{3 b - 5 c}$ (Fig. 1). However, compounds 3a, 4a and 5a in this series (Fig. 1) have been prepared by the reaction of $\mathbf{1 \mathbf { a } ^ { \prime }}$ with propargyl alcohol (3a), $\mathbf{1} \mathbf{b}^{\prime}$ with propargylic acid (4a) and $\mathbf{1} \mathbf{c}^{\prime}$ again with propargylic acid (5a). All these compounds were characterized by NMR and Mass spectroscopic methods. ${ }^{13} \mathrm{C}$ NMR spectrum of all the compounds displayed a signal at about $\delta_{\mathrm{C}} 180 \mathrm{ppm}$ characteristics for $>\mathrm{CO}$ group at $\mathrm{C}-4$ in chrysin which indicates that chrysin unit was present in all the compounds. ${ }^{13} \mathrm{C}$ NMR spectrum also displayed the signals for aromatic carbons at $\delta_{\mathrm{C}}$ about 164 (C-7, C-2), 157-162 (C-5, C-9), 125-132 (C-12 to C-62), 93-110 (C-3, C-6, C-8, C-10) characteristics of chrysin unit and clearly supported the presence of this unit in all the compounds. Furthermore, ${ }^{1} \mathrm{H}$ NMR spectrum of all the compounds also corroborated the presence of chrysin unit in the compounds. In particular, the proton resonance at $\delta_{\mathrm{H}}$ about $13 \mathrm{ppm}$ which corresponds to $5-\mathrm{OH}$ (chelated with $>\mathrm{CO}$ at $\mathrm{C}-4$ in chrysin unit) along with $\delta_{\mathrm{H}}$ values at about 6-8 ppm (due to the other protons in chrysin unit) was a clear indication of the presence of chrysin unit in all the compounds. ${ }^{13} \mathrm{C}$ NMR-DEPT $\left(90^{\circ}\right.$ and $135^{\circ}$ ) experiments were also carried out to ascertain the number of methyl, methylene, methine and quaternary carbons in all the compounds. ${ }^{1} \mathrm{H}$ and ${ }^{13} \mathrm{C}$ NMR spectral data of all individual compounds were in good agreement with the desired structure of the respective compounds (Fig. 1). In addition, GCMS analysis was also used to authenticate the anticipated molecular weight and molecular formula of each compound to establish their molecular structure.

Screening of antimicrobial activity by Agar well diffusion method: Screening for antimicrobial activities of all the derivatives was done against different bacterial and fungal strains by agar well diffusion method according to NCCLS method. Experimental results indicated varying degrees of microbial 
inhibition (Table-1) against the selected Gram-positive bacteria viz. Bacillus subtilis (MTCC 121), Shigella dysenteriae, Streptococcus pneumoniae (MTCC 655); Gram-negative bacteria viz. Klebsiella pneumoniae (MTCC 3384), Pseudomonas aeruginosa (MTCC 424), Escherichia coli (MTCC 443) and fungi viz. Candida albicans (MTCC 227), Candida tropicalis. Among the various test compounds only $\mathbf{2} \mathbf{a}, \mathbf{2} \mathbf{e}$ and $\mathbf{2} \mathbf{i}$ showed excellent antibacterial activity against almost all the Gram-positive and Gram-negative bacteria while most of the other compounds showed comparatively low to moderate values of such activities. Critical analyses of the structural modifications done in all the derivatives appears that amino alkyl like substitutes in the C-7-O-position of chrysin was positive for higher antimicrobial activity against all the selected antimicrobial strains. On the other hand it was observed that amino aryl like substitutes in the C-7-O-position of chrysin executed a detrimental effect towards antimicrobial activity. In $\mathbf{2} \mathbf{a}, \mathbf{2} \mathbf{e}$ and $\mathbf{2} \mathbf{i}$ due to the presence of amino alkyl like substitutes in the $\mathrm{C}-7-\mathrm{O}$ position showed higher activities among the test compounds. Low activities of triazole derivatives may be attributed to the aromatic nature of the triazole ring at C-7-O position of chrysin. Moreover, it was found that even on increasing the alkyl nature through spacer length $(2 \rightarrow 4)$ the detrimental effect of triazole ring prevails.
The MIC (minimum inhibitory concentration) values, i.e. the lowest concentration that fully inhibits the visible (unaided eye) growth of the organisms were determined only for the most active compounds viz. $\mathbf{2 a}, \mathbf{2} \mathbf{e}$ and $\mathbf{2 i}$. It was observed that lowest MIC values of compound 2a was 15.7 in case of $S$. dysenteriae whereas lowest MIC values of compound $\mathbf{2 e}$ and 2i were 15.3 and 14 against $E$. coli and $S$. dysenteriae, respectively. On the other hand, highest MIC values of compound 2a was 17.0 in case of $P$. aeruginosa and highest MIC values of compound $\mathbf{2 e}$ and $\mathbf{2} \mathbf{i}$ were 17.7 and 16.3 respectively, against K. pneumoneae (Table-2).

In case of minimum bactericidal concentration (MBC), lowest value was found at $17 \mu \mathrm{g} / \mathrm{mL}$ for $2 \mathbf{i}$ against $E$. coli and $S$. dysenteriae whereas the highest value was observed at 20 $\mu \mathrm{g} / \mathrm{mL}$ for $\mathbf{2 a}$ and $\mathbf{2 e}$ against K. pneumoniae, S. pneumoniae and $P$. aeruginosa (Table-3).

In antibiofilm activity study two bacterial strains viz. $S$. pneumoeiae (Gram-negative) and K. pneumoeiae (Grampositive) were used as both of them are standard biofilm forming strains. In the crystal violet assay [39] (Fig. 2a) it has been found that biofilm formation of the experimental human pathogens viz. S. pneumoeiae (Gram-negative) and K. pneumoeiae (Gram-positive) was significantly $(\mathrm{p}<.05)$ inhibited by $\mathbf{2 a}, \mathbf{2 e}$

\begin{tabular}{|c|c|c|c|c|c|c|c|c|}
\hline \multirow[b]{3}{*}{ Compounds } & \multirow{2}{*}{\multicolumn{6}{|c|}{ 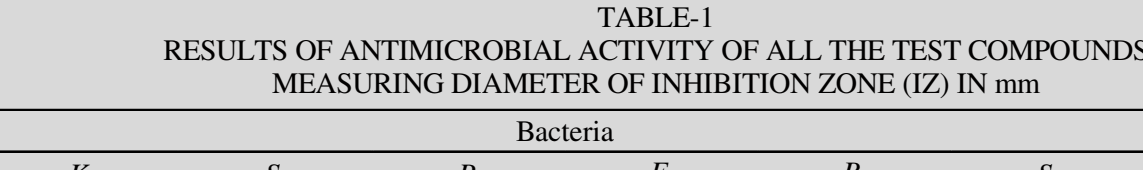 }} & \multirow{2}{*}{\multicolumn{2}{|c|}{ Fungi }} \\
\hline & & & & & & & & \\
\hline & $\begin{array}{c}K . \\
\text { pneumoniae }\end{array}$ & $\begin{array}{c}S . \\
\text { pneumoniae }\end{array}$ & $\begin{array}{c}P . \\
\text { aeruginosa }\end{array}$ & $\begin{array}{c}E . \\
\text { coli }\end{array}$ & $\begin{array}{c}\text { B. } \\
\text { subtilis }\end{array}$ & $\begin{array}{c}S . \\
\text { dysenteriae }\end{array}$ & $\begin{array}{c}C . \\
\text { albicans }\end{array}$ & $\begin{array}{c}C . \\
\text { tropicalis }\end{array}$ \\
\hline $2 a$ & $22 \pm 0.76$ & $20 \pm 0.61$ & $23 \pm 0.84$ & $18 \pm 0.47$ & $22 \pm 0.76$ & $21 \pm 0.51$ & $20 \pm 0.53$ & $17 \pm 0.46$ \\
\hline $2 b$ & $8 \pm 0.43$ & $7 \pm 0.21$ & $7 \pm 0.19$ & $7 \pm 0.42$ & $7 \pm 0.21$ & $7 \pm 0.19$ & $8 \pm 0.25$ & $8 \pm 0.35$ \\
\hline $2 c$ & NA & NA & $7 \pm 0.36$ & $8 \pm 0.45$ & $8 \pm 0.36$ & $8 \pm 0.43$ & NA & $7 \pm 0.36$ \\
\hline 2d & $7 \pm 0.36$ & $7 \pm 0.19$ & $8 \pm 0.21$ & $7 \pm 0.36$ & NA & $8 \pm 0.41$ & NA & NA \\
\hline $2 e$ & $17 \pm 0.36$ & $16 \pm 0.31$ & $16 \pm 0.29$ & $15 \pm 0.46$ & $18 \pm 0.18$ & $17 \pm 0.26$ & $16 \pm 0.36$ & $15 \pm 0.37$ \\
\hline $2 f$ & $8 \pm 0.42$ & $7 \pm 0.21$ & $8 \pm 0.36$ & $7 \pm 0.36$ & $7 \pm 0.42$ & $7 \pm 0.36$ & $7 \pm 0.00$ & $7 \pm 0.00$ \\
\hline $2 \mathrm{~g}$ & NA & NA & $7 \pm 0.21$ & $8 \pm 0.00$ & $8 \pm 0.36$ & $8 \pm 0.43$ & $7 \pm 0.00$ & NA \\
\hline $2 \mathrm{~h}$ & $7 \pm 0.00$ & $7 \pm 0.19$ & $8 \pm 0.42$ & $7 \pm 0.36$ & $8 \pm 0.43$ & $8 \pm 0.41$ & NA & $7 \pm 0.42$ \\
\hline $2 \mathbf{i}$ & $20 \pm 0.61$ & $18 \pm 0.47$ & $18 \pm 0.26$ & $23 \pm 0.84$ & $17 \pm 0.29$ & $19 \pm 0.64$ & $17 \pm 0.41$ & $22 \pm 0.68$ \\
\hline 3a & $8 \pm 0.48$ & $7 \pm 0.19$ & $9 \pm 0.32$ & $07 \pm 0.19$ & $08 \pm 0.18$ & $9 \pm 0.14$ & $8 \pm 0.44$ & $9 \pm 0.41$ \\
\hline $3 b$ & $8 \pm 0.36$ & $7 \pm 0.36$ & $7 \pm 0.42$ & $8 \pm 0.00$ & $8 \pm 0.36$ & $8 \pm 0.43$ & NA & NA \\
\hline $3 c$ & NA & NA & $7 \pm 0.21$ & $08 \pm 0.18$ & NA & NA & $7 \pm 0.19$ & $9 \pm 0.36$ \\
\hline $4 a$ & NA & NA & NA & NA & NA & $8 \pm 0.43$ & NA & $7 \pm 0.36$ \\
\hline $4 b$ & NA & NA & NA & $7 \pm 0.36$ & $7 \pm 0.19$ & $8 \pm 0.43$ & NA & NA \\
\hline $4 c$ & $8 \pm 0.26$ & $7 \pm 0.12$ & $9 \pm 0.21$ & $07 \pm 0.12$ & $09 \pm 0.21$ & $7 \pm 0.19$ & $7 \pm 0.19$ & $8 \pm 0.18$ \\
\hline $5 \mathbf{a}$ & $7 \pm 0.42$ & NA & $7 \pm 0.21$ & NA & NA & $8 \pm 0.43$ & NA & $7 \pm 0.36$ \\
\hline $5 b$ & NA & NA & $7 \pm 0.19$ & $8 \pm 0.00$ & $8 \pm 0.36$ & $8 \pm 0.21$ & NA & NA \\
\hline $5 c$ & $7 \pm 0.42$ & $7 \pm 0.42$ & $8 \pm 0.31$ & $07 \pm 0.19$ & $9 \pm 0.37$ & $9 \pm 0.22$ & $8 \pm 0.42$ & $8 \pm 0.42$ \\
\hline Streptomycin & $17 \pm 0.46$ & $19 \pm 0.51$ & $17 \pm 0.41$ & $18 \pm 0.18$ & $15 \pm 0.48$ & $23 \pm 0.92$ & ND & ND \\
\hline
\end{tabular}

TABLE-2

RESULTS OF MINIMUM INHIBITORY CONCENTRATION (MIC) OF 2a, 2e AND 2i $(\mu \mathrm{g} / \mathrm{mL})$

\begin{tabular}{|c|c|c|c|c|c|c|c|c|}
\hline \multirow[b]{2}{*}{ Compounds } & \multicolumn{6}{|c|}{ Bacteria } & \multicolumn{2}{|c|}{ Fungi } \\
\hline & $\begin{array}{c}\text { K. } \\
\text { pneumoneae }\end{array}$ & $\begin{array}{c}\text { S. } \\
\text { pneumoniae }\end{array}$ & $\begin{array}{c}P . \\
\text { aeruginosa }\end{array}$ & $\begin{array}{c}E . \\
\text { coli }\end{array}$ & $\begin{array}{c}B . \\
\text { subtilis }\end{array}$ & $\begin{array}{c}. \\
\text { dysentrae }\end{array}$ & $\begin{array}{c}C . \\
\text { albicans }\end{array}$ & $\begin{array}{c}C . \\
\text { tropicalis }\end{array}$ \\
\hline $2 a$ & 16.7 & 16.3 & 17.0 & 16.0 & 16.7 & 15.7 & 15.3 & 16.3 \\
\hline $2 e$ & 17.7 & 16.7 & 17.3 & 15.3 & 15.6 & 16.3 & 16.7 & 16.0 \\
\hline $2 \mathbf{i}$ & 16.3 & 15.7 & 16.0 & 14.6 & 15.3 & 14.0 & 15.7 & 15.3 \\
\hline Streptomycin & 15.0 & 13.0 & 14.7 & 13.3 & 13.3 & 13.5 & ND & ND \\
\hline
\end{tabular}

Values are the mean of triplicates. ND- Not done. 


\begin{tabular}{lcccc}
\hline \multicolumn{5}{c}{ TABLE-3 } \\
MINIMUM BACTERICIDAL \\
CONCENTRATION (MBC) OF 2a-i $(\mu \mathrm{g} / \mathrm{mL})$ \\
\hline \multirow{5}{c}{ Compounds } \\
\cline { 2 - 5 } \multicolumn{1}{c}{ Microorganisms } & $\mathbf{2 a}$ & $\mathbf{2 e}$ & $\mathbf{2 i}$ & $\begin{array}{c}\text { Strepto- } \\
\text { mycin }\end{array}$ \\
\hline Klebsiella pneumoneae & 20 & 20 & 19 & 17 \\
Streptococcus pneumoniae & 20 & 20 & 19 & 15 \\
Pseudomonas aeruginosa & 20 & 20 & 19 & 16 \\
Escherichia coli & 19 & 19 & 17 & 15 \\
Bacillus subtilis & 19 & 19 & 18 & 15 \\
Shigella dysentrae & 19 & 19 & 17 & 16 \\
\hline
\end{tabular}

and $2 \mathbf{i}$ at their respective MIC values. On a separate treatment of $K$. pneumoeiae and S. pneumoniae with $60 \mu \mathrm{g} / \mathrm{mL}$ of all the potential derivatives followed by an incubation period of $24 \mathrm{~h}$ at $37^{\circ} \mathrm{C}$ it was observed that biofilm formation was inhibited by more than $90 \%$. However, further increase of the concentration of the test compounds to $100 \mu \mathrm{g} / \mathrm{mL}$ and beyond did not show any significant differences of biofilm inhibition (Fig. 2b) at all.

Acridine orange is a cell membrane-permeable dye that can bind with DNA and RNA in the cell and stain all cells making a green fluorescence in the sample. On the other hand ethidiumbromide also a strong DNA binder but can stain cells that are dead or in the final stages of death and make a red fluorescence [40]. In our experiment we observed a clear green fluorescence (Fig. 3A) in absence of test compounds (control) while on increasing the concentration of test compounds red fluorescence gradually increases (Fig. 3B-3C) indicating the inhibition of bacterial cell viability.

Finally, for hemolytic activity study only the preliminary experiment has been done to know whether these active compounds show any hemolytic activity. Experimental results in agar diffusion technique on blood agar indicated that all the three potential compounds $(\mathbf{2} \mathbf{a}, \mathbf{2} \mathbf{e}$ and $\mathbf{2 i})$ did not have any hemolytic activity.

\section{Conclusion}

This study explored some newly synthesized chrysin derivatives as antibacterial, antifungal and antibiofilm agents. In this study it revealed that triazole derivatives were less effective than amine derivatives towards selected bacterial strains. This study further depicted that C-7-O position of chrysin is very much susceptible towards antimicrobial activity and alkyl group, preferably cycloalkyl substitutes are more effective than aryl substituents. Therefore, this study would be helpful to design and development of antimicrobial agents through structural modulation of natural chrysin which has an encouraging biological profile and is frequently occurring in various plants and vegetables.

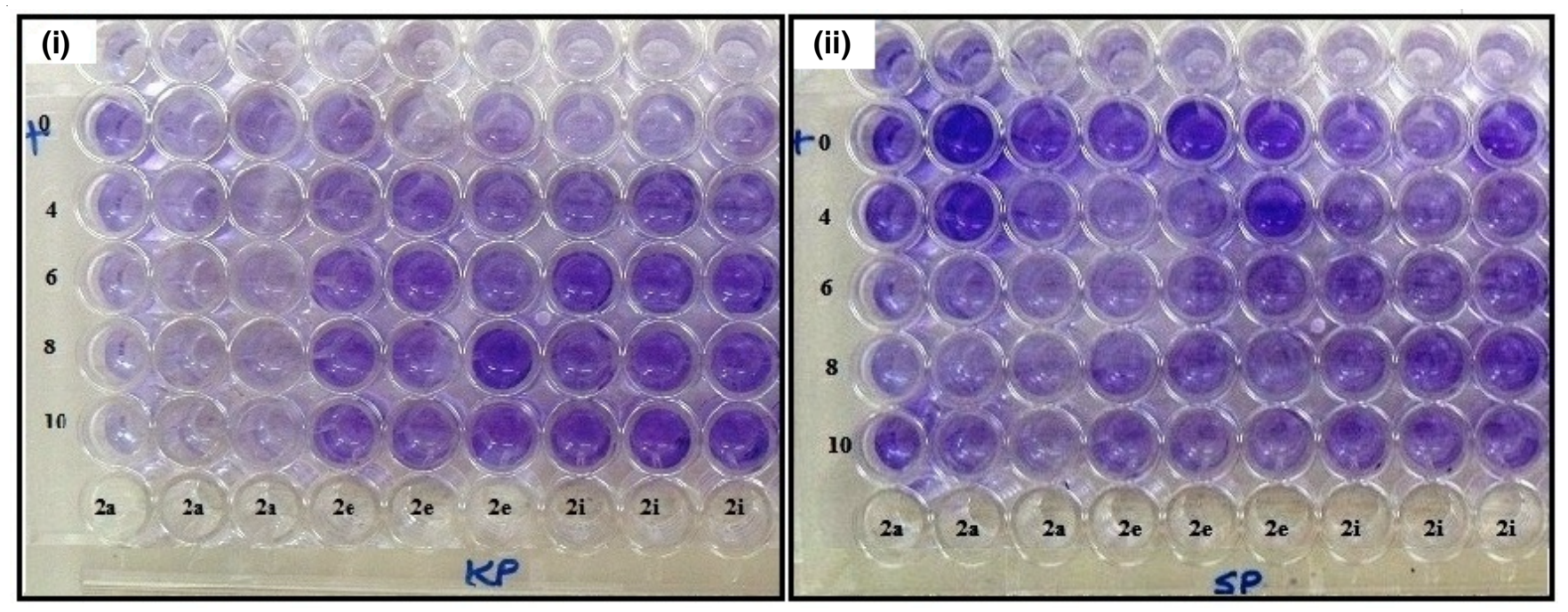

Fig. 2a. Crystal violet assay for antibiofilm activity determination of the most active compounds $\mathbf{2 a}$, 2e and $\mathbf{2 i}$ against (i) K. pneumoeiae (KP) (ii) S. pneumoeiae (SP)
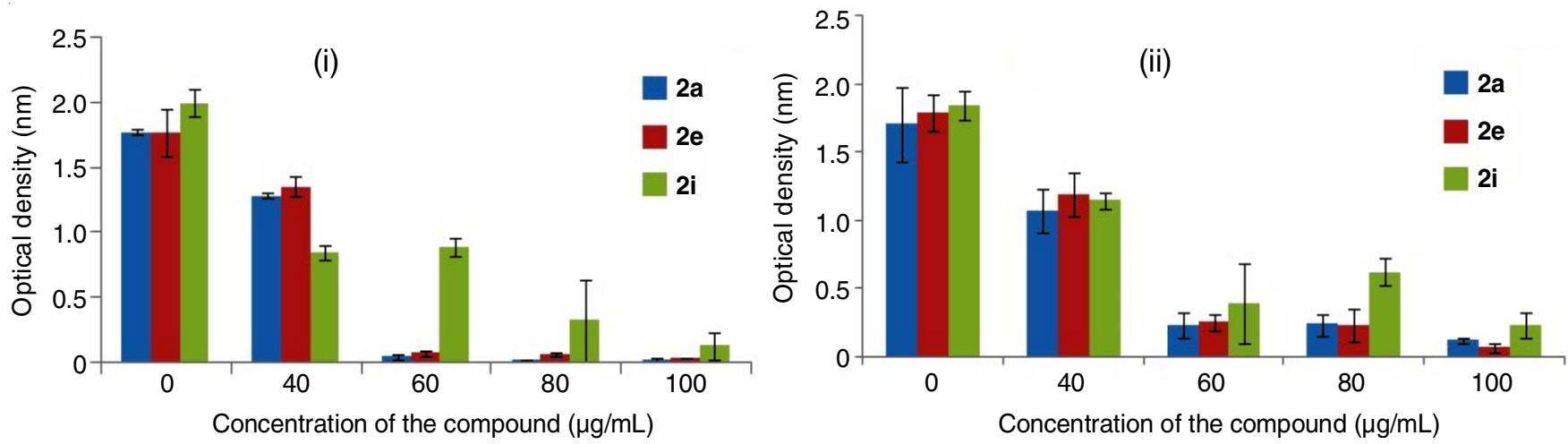

Fig. 2b. Comparative analysis of antibiofilm activity of the compounds $\mathbf{2 a}, \mathbf{2 e}$ and $\mathbf{2} \mathbf{i}$ against- (i). K. pneumoniae. (ii). S. pneumoniae 


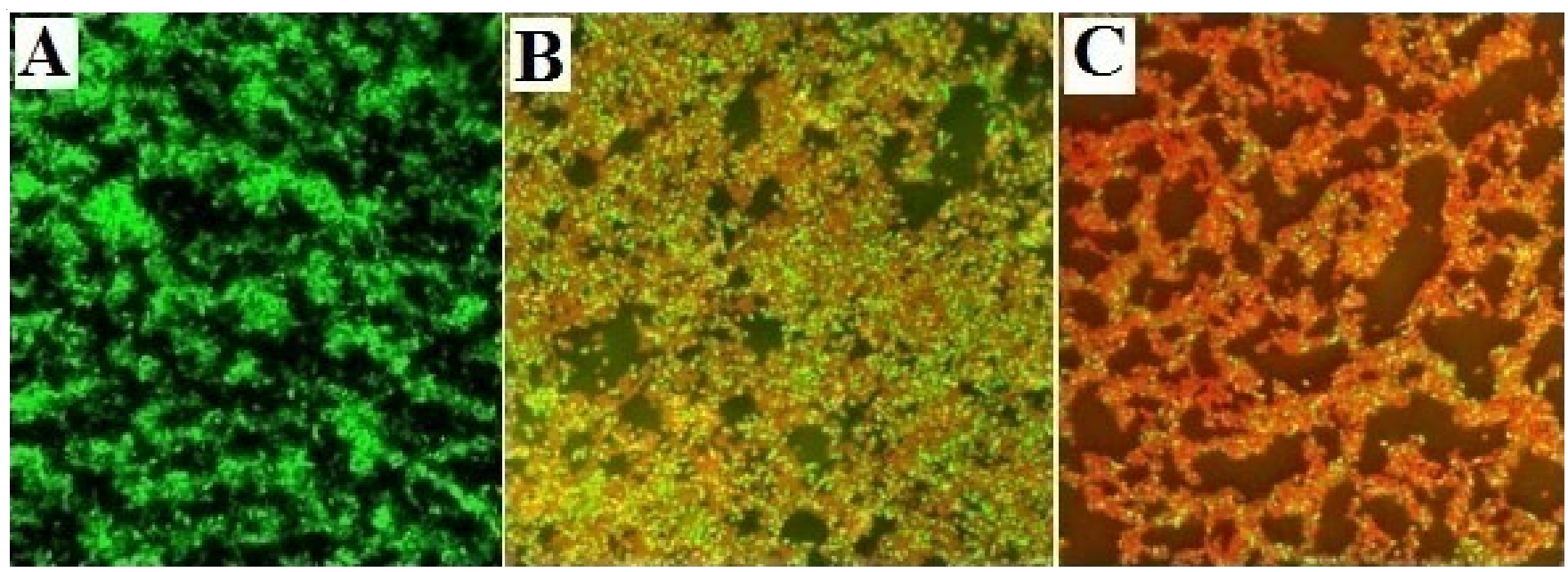

Fig. 3. Fluorescence microscopy images of cell viability staining assay of Klebsiella pneumoniae biofilm by acridine orange and ethidium bromide with a test compound (2a). Green fluorescence (acridine orange) represents the viable live cells; Red fluorescence (ethidium bromide) indicates damaged/dead cells for A. Control-without test compound B. at $60 \mu \mathrm{g} / \mathrm{mL}$ concentration of test compound C. at $100 \mu \mathrm{g} / \mathrm{mL}$ concentration of test compound

\section{ACKNOWLEDGEMENTS}

The authors acknowledge the partial financial help of DBT, Government of India via twining project (BT/526/NE/TBP/ 2013). One of the authors, S. Bhowmik also acknowledges to DBT, Government of India for providing Junior Research Fellowship. The authors also acknowledge the help of State Biotech Hub, Tripura University for providing various facilities.

\section{REFERENCES}

1. L.L. Silver, Microbiol. Rev., 24, 71 (2011); https://doi.org/10.1128/CMR.00030-10.

2. G.M. Cragg and D.J. Newman, Biochim. Biophys. Acta, 1830, 3670 (2013); https://doi.org/10.1016/i.bbagen.2013.02.008

3. A. Giacometti, O. Cirioni, A.M. Schimizzi, M.S. Del Prete, F. Barchiesi, M.M. D’Errico, E. Petrelli and G. Scalise, J. Clin. Microbiol., 38, 918 (2000).

4. V.E. Wagner and B.H. Iglewski, Clin. Rev. Allergy Immunol., 35, 124 (2008); https://doi.org/10.1007/s12016-008-8079-9.

5. M.C. Das, S. Paul, P. Gupta, P. Tribedi, S. Sarkar, S. Bhattacharjee and D. Manna, J. Appl. Microbiol., 120, 842 (2016);

https://doi.org/10.1111/jam.13063.

6. A. Adonizio, K.F. Kong and K. Mathee, Antimicrob. Agents Chemother. 52, 198 (2008); https://doi.org/10.1128/AAC.00612-07.

7. S. Ponnuswamy, A. Akila, D.D. Rajakumari, S. Suressh and G. Usha, J. Chem. Sci., 127, 2051 (2015); https://doi.org/10.1007/s12039-015-0974-Z.

8. H. Sudhamani, S.T. Basha, N. Venkateswarlu, T. Vijaya and C.N. Raju, J. Chem. Sci., 127, 1739 (2015);

https://doi.org/10.1007/s12039-015-0935-6.

9. M. Zayane, A. Romdhane, M. Daami-Remadi and H.B. Jannet, J. Chem. Sci., 127, 1619 (2015); https://doi.org/10.1007/s12039-015-0927-6.

10. A.B. Reddy, R.V.Hymavathi and G.N. Swamy, J. Chem. Sci., 125, 495 (2013); https://doi.org/10.1007/s12039-013-0417-7.

11. A. Bishnoi, S. Singh, A.K. Tiwari, K. Srivastava, R. Raghuvir and C.M. Tripathi, J. Chem. Sci., 125, 305 (2013); https://doi.org/10.1007/s12039-013-0367-0.

12. A. Saundane, M. Yarlakatti, P. Walmik and V.I. Katkarf, J. Chem. Sci., 124, 469 (2012);

https://doi.org/10.1007/s12039-011-0180-6.

13. R. Kharb, M. Shahar Yar and P.C. Sharma, Curr. Med. Chem., 18, 3265 (2011);

https://doi.org/10.2174/092986711796391615.
14. A. Sharma, V. Kumar, R. Kharb, S. Kumar, P.C. Sharma and D.P. Pathak, Curr. Pharm. Des., 22, 3265 (2016); https://doi.org/10.2174/1381612822666160226144333.

15. R. Kharb, P.C. Sharma and M.S. Yar, J. Enzyme Inhib. Med. Chem., 26, 1 (2011); https://doi.org/10.3109/14756360903524304.

16. P.C. Sharma, P. Seema, K.K. Bansal and A. Saini, Chem. Biol. Lett., 4, 63 (2017).

17. B. Kedika, K. Thotla, V. Noole and K.R. Chepyala, J. Chem. Pharm. Res., 8, 1210 (2016).

18. L.H. Cazarolli, L. Zanatta, E.H. Alberton, M.S. Figueiredo, P. Folador, R.G. Damazio, M.G. Pizzolatti and F.R. Silva, Mini Rev. Med. Chem., 8, 1429 (2008); https://doi.org/10.2174/138955708786369564.

19. Y. Liu, X. Song, J. He, X. Zheng and H. Wu, Med. Chem. Res., 23, 555 (2014); https://doi.org/10.1007/s00044-013-0711-4.

20. H. Park, T.T. Dao and H.P. Kim, Eur. J. Med. Chem., 40, 943 (2005); https://doi.org/10.1016/j.ejmech.2005.04.013.

21. Q.W. Shi, X.H. Su and H. Kiyota, Chem. Rev., 108, 4295 (2008); https://doi.org/10.1021/cr078350s.

22. K.S. Lam, Trends Microbiol., 15, 279 (2007); https://doi.org/10.1016/j.tim.2007.04.001.

23. E. Brown, N.S. Hurd, S. McCall and T.E. Ceremuga, Am. Assoc. Nurse. Anes. J., 5, 333 (2007).

24. E. Leonard, Y. Yan, K.H. Lim and M.A. Koffas, Appl. Environ. Microbiol., 71, 8241 (2005);

https://doi.org/10.1128/AEM.71.12.8241-8248.2005.

25. X. Zheng, W.D. Meng, Y.Y. Xu, J.G. Cao and F.L. Qing, Bioorg. Med. Chem. Lett., 13, 881 (2003); https://doi.org/10.1016/S0960-894X(02)01081-8.

26. Z.Y. Zhu, W.X. Wang, Z.Q. Wang, L.J. Chen, J.Y. Zhang, X.C. Liu, S.P. Wu and Y.M. Zhang, Eur. J. Med. Chem., 75, 297 (2014); https://doi.org/10.1016/j.ejmech.2013.12.044.

27. T. Zhang, X. Chen, L. Qu, J. Wu, R. Cui and Y. Zhao, Bioorg. Med. Chem., 12, 6097 (2004); https://doi.org/10.1016/j.bmc.2004.09.013.

28. L.P. Sun, A.L. Chen, H.C. Hung, Y.H. Chien, J.S. Huang, C.Y. Huang, Y.W. Chen and C.N. Chen, J. Agric. Food Chem., 60, 11748 (2012); https://doi.org/10.1021/if303261r.

29. I.C. Villar, R. Jimenez, M. Galisteo, M. Garcia-Saura, F.A. Zarzuelo and J. Duarte, Planta Med., 68, 847 (2002); https://doi.org/10.1055/s-2002-34400.

30. G.K. Harris, Y. Qian, S.S. Leonard, D.C. Sbarra and X. Shi, J. Nutr., 136, 1517 (2006); https://doi.org/10.1093/jn/136.6.1517.

31. K. Hu, W. Wang, H. Cheng, S.S. Pan and J. Ren, Med. Chem. Res., 20, 838 (2011); https://doi.org/10.1007/s00044-010-9395-1. 
32. M.C. Das, P. Sandhu, P. Gupta, P. Rudrapaul, U.C. De, P. Tribedi, Y. Akhter and S. Bhattacharjee, Sci. Rep., 6, 23347 (2016); https://doi.org/10.1038/srep23347.

33. M.V. Veselovskaya, M.M. Garazd, A.S. Ogorodniichuk, Y.L. Garazd and V.P. Khilya, Chem. Nat. Compd., 44, 704 (2008); https://doi.org/10.1007/s10600-009-9194-4.

34. Q. Li, L. Shi, Q.-S. Li, P.-G. Liu, Y. Luo, J. Zhao and H.-L. Zhu, Bioorg. Med. Chem., 17, 6264 (2009); https://doi.org/10.1016/j.bmc.2009.07.046.

35. K. Suresh Babu, T. Hari Babu, P.V. Srinivas, K. Hara Kishore, U.S.N. Murthy and J.M. Rao, Bioorg. Med. Chem. Lett., 16, 221 (2006); https://doi.org/10.1016/j.bmcl.2005.09.009.

36. A. Giacometti, O. Cirioni, F. Barchiesi, M.S. Del Prete, M. Fortuna, F. Caselli and G. Scalise, Antimicrob. Agents Chemother., 44, 1694 (2000); https://doi.org/10.1128/AAC.44.6.1694-1696.2000.
37. D. Ribble, N.B. Goldstein, D.A. Norris and Y.G. Shellman, BMC Biotechnol., 5, 12 (2005); https://doi.org/10.1186/1472-6750-5-12.

38. S. Kasibhatla, G.P. Amarante-Mendes, D. Finucane, T. Brunner, E. BossyWetzel and D.R. Green, Cold Spring Harb. Protoc., 3, 4493 (2006); https://doi.org/10.1101/pdb.prot4465.

39. C.S. Stepanovic, M.L. Cirkoric, L. Ranin and A.L. Svabicviahocic, Appl. Microbiol., 28, 326 (2004).

40. D. Baskic, S. Popovic, P. Ristic and N. Arsenijevic, Cell Biol. Int., 30, 924 (2006);

https://doi.org/10.1016/i.cellbi.2006.06.016. 